\title{
A STUDY OF THE RELATION BETWEEN THE BRINELL HARDNESS AND THE GRAIN SIZE OF ANNEALED CARBON STEELS
}

\author{
By Henry S. Rawdon and Emilio Jimeno-Gil
}

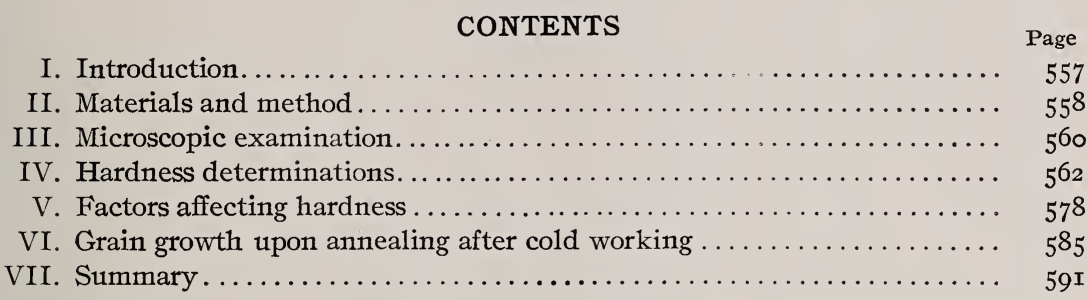

\section{INTRODUCTION}

It is a matter of common agreement among metallurgists and users of metals in general that the "grain size" of metals and alloys is a factor of fundamental importance in determining the characteristic properties of the material. There is, however, no such common agreement as to which of the mechanical properties is most profoundly affected by differences in grain size, or to what extent the grain size may be used as a measure of such properties. Much of the distrust with which a coarsely granular metal, particularly steel, is received is largely a matter of the combined experiences common to all metallurgists rather than to any particular investigation along this line. The subject of grain size has received a very considerable amount of attention. The extensive studies of Jeffries stand foremost ${ }^{1}$ in the list.

Howe ${ }^{2}$ and Gulliver ${ }^{3}$ have also made noteworthy contributions to the subject. In these studies attention was directed principally to the conditions necessary for the occurrence of grain growth and to the means of measuring such growth. The relation between grain size and mechanical properties, such as are measured in the ordinary methods of testing, was not made the primary object of the studies. Most of the work on grain size in metals has been

1 Two of the most important references to this author's work are: $Z$. Jeff ries, Grain-GrowthPhenomena in Metals, Bull. Am. Inst. Min. Engrs., 56, p. 571, I9г6, and Effect of Temperature, Deformation, and Grain Size on the Mechanical Properties of Metals, Am. Inst. Min. Engrs., I9I9. Previous articles by the same author are summarized and discussed in full in the second article.

${ }^{2}$ H. M. Howe, Grain Growth, Bull. Am. Inst. Min. Engrs., 56, p. 582; rgr6.

${ }^{3}$ G. H. Gulliver, Grain Size, Jour. Inst. Metals, 19, No. I, p. I45; I918. 
based also upon materials of relatively simple structure; for instance, simple metals and one-constituent alloys. Among the few attempts made to correlate the results of grain-size determinations with the mechanical properties of the metal may be mentioned the rather comprehensive study by Bassett and Davis ${ }^{4}$ upon $\alpha$ brass. It was shown that for brasses of the same composition which had previously received a similar mechanical treatment a rather definite relation exists between the Brinell hardness and the average size of crystals comprising the material. In discussing this work Mathewson ${ }^{5}$ has shown that a formula may be derived which expresses this relationship rather closely. But little work, however, has been done to establish such a relationship for steels, if such a one does exist. The studies made by McAdam upon the grain size of soft steel ${ }^{6}$ have been in the direction of defining the conditions by which grain growth may occur in such material rather than in developing the relationship of the properties of the material to the grain size of the same. The work of Pomp $^{7}$ which appears to be the most comprehensive study in this field, was restricted to only one type of material, a steel of o.o8 per cent carbon content being used throughout. While such a steel permits of an accurate grain size determination more readily than do others higher in carbon, a knowledge of mechanical properties of this material is of much less industrial importance than of the steels of higher carbon content. The work herein discussed was undertaken to determine to what extent the mechanical hardness of steels of different carbon contents is dependent upon grain size and to show also what other factors are contributory. It is hoped that the work will be extended later to cover the relation of grain size to the mechanical properties of steels other than hardness.

\section{MATERIALS AND METHOD}

The general plan of study included the determination of the hardness of specimens which were of the same composition but differed widely in their grain size. The material used comprised five steels of the composition shown in Table I. Since it was desired to express the grain size numerically, if possible, the different steels were chosen with this in view. Hence material of approximately eutectoid composition was avoided.

${ }_{4} \mathrm{~W}$. H. Bassett and C. H. Davis, Comparison of Grain-Size Measurements and Brinell Hardness of Cartridge Brass, Bull. Am. Inst. Min. and Met. Engrs., p. 692; I919.

${ }^{5} \mathrm{C}$. H. Mathewson, Discussion of Bassett and Davis's paper.

${ }^{6}$ D. J. MrcAdam, jr., Proc. A. S. T. MI., 17, Pt. II, p. 58; 1917. Also, 18, Pt. II, p. 68; I9r8.

7 A. Pomp, Einfluss der Wärmbehandlung auf die Kerbzähigkeit, Korngrösse und Härte von kohlen stoffarmem Flusseisen. Ferrum, 13, p. 49; I915-I6. 
TABLE 1.-Results of Chemical Analyses of Steels Usea $a$

\begin{tabular}{|c|c|c|c|c|c|}
\hline Specimen & Carbon & Manganese & Phosphorus & Sulphur & Silicon \\
\hline & Per cent & Per cent & Per cent & Per cent & Per cent \\
\hline A... & 0.07 & 0.27 & 0.006 & 0.054 & 0.002 \\
\hline B... & .19 & .41 & .004 & .050 & .002 \\
\hline C.................... & .46 & .36 & .019 & .047 & .060 \\
\hline D.............. & .70 & .22 & .023 & .011 & .227 \\
\hline E................... & 1. 12 & .23 & .019 & .013 & .223 \\
\hline
\end{tabular}

$a$ Much of the material was furnished through the courtesy of the Carnegie Steel Co.

In order to develop grains varying widely in size, two different methods were adopted. In the first the specimens (two-inch lengths of bars, one by one-half inch cross section) were heated for six hours at various temperatures, as shown in Table 2. Two specimens of each composition were heated at each of the temperatures indicated; one was cooled slowly in the furnace at the close of the six-hour period, the other allowed to cool more rapidly in the air. For each particular temperature the specimens were all heated together (likewise cooled together) in order to eliminate possible effects from variations in heating conditions. For heating, an electric-resistance furnace of the muffle type was used for the four lower temperatures, and the higher temperatures were obtained in a small gas-fired muffle furnace. The temperature measurements were made by means of a chromel-alumel thermocouple and a small portable potentiometer. In order to avoid decarburization during the continued heating at the high temperatures (974, 1024, and I I $2^{\circ} \mathrm{C}$, Table 2 ), the specimens were packed in a mixture of amorphous silica and 5 per cent of powdered charcoal. This was found, by trial, to be very effective in retarding decarburization; only a relatively thin layer was affected. When the specimens were prepared for the microscopic examination and the determination of hardness, they were ground deeply enough to remove entirely the decarburized layer.

The second method for producing variations in grain size consisted in annealing bars after they had been given a preliminary cold working by stressing in tension. This is discussed in detail in Section VI. 
TABLE 2.-Annealing Temperatures and Methods of Cooling Specimens

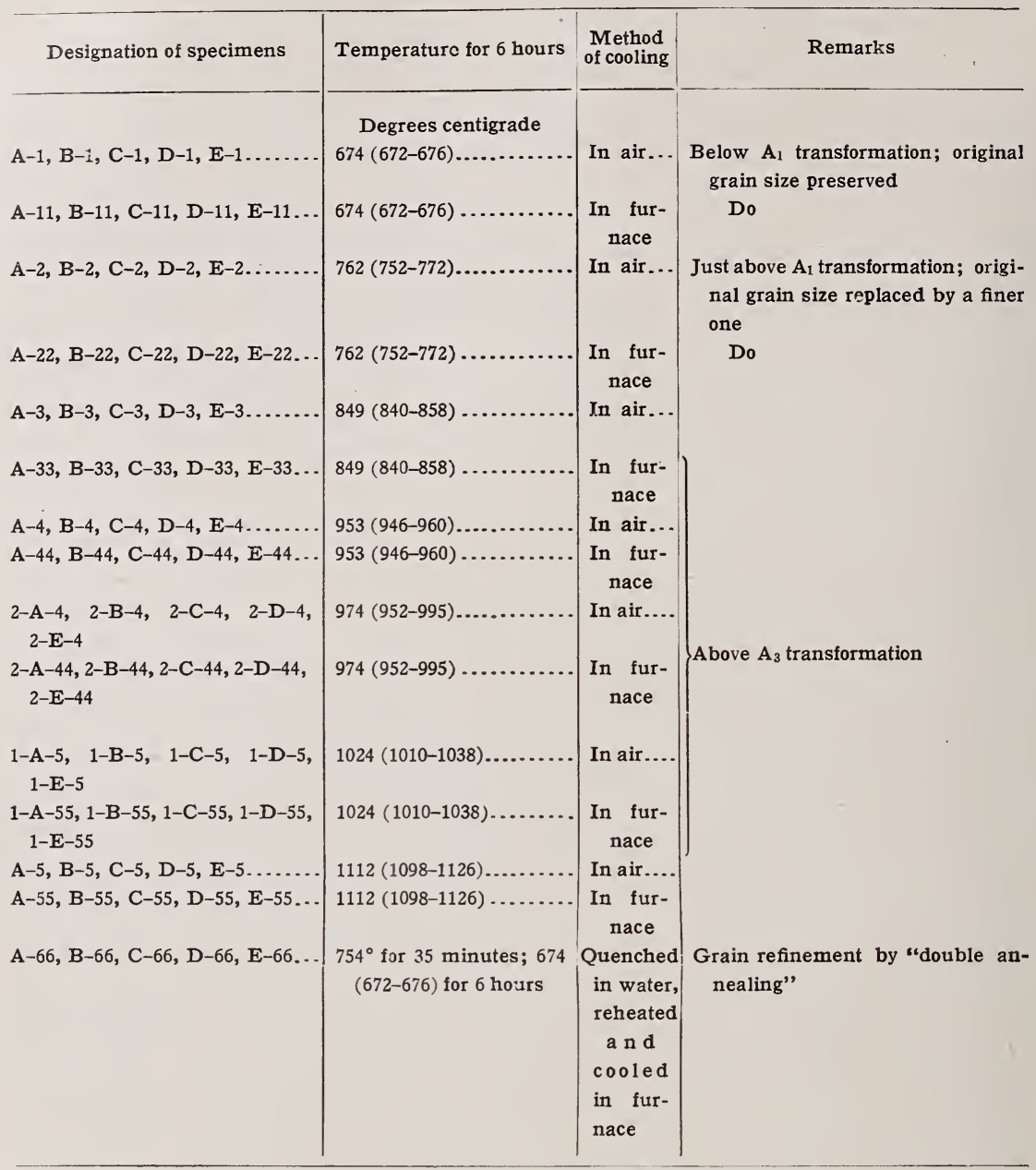

\section{MICROSCOPIC EXAMINATION}

The specimens were examined microscopically and a grain size determination was attempted. The method used was the planimetric one, modified and described by Jeffries ${ }^{8}$ and adopted by the American Society for Testing Materials in its tentative specifications for the preparation of micrographs. ${ }^{9}$

In Table 3 are summarized the results of the grain count. Only for the steels of the low-carbon content (particularly those cooled in air) and heated at the highest temperatures could a satisfactory grain-size determination be made with certainty.

${ }^{8}$ Z. Jeffries, Am. Inst. Min. Engrs., 54, p. 594; I9I6. Also, Mlet. and Chem. Eng., 18, p. I85; I9I8.

9 Tentative Spec. E ${ }_{2-19}$ T, Proc, A. S. T. M., 19, Pt. I, p. 770; I9I9. 
TABLE 3.-Results of Grain-Size Determination

\begin{tabular}{|c|c|c|c|c|c|c|c|}
\hline Specimen, air cooled & $\begin{array}{c}\text { Average } \\
\text { tempera- } \\
\text { ture of } \\
\text { heating }\end{array}$ & $\begin{array}{l}\text { Number } \\
\text { of grains } \\
\text { per } \mathrm{mm}^{2}\end{array}$ & $\begin{array}{l}\text { Area of } \\
\text { grain } \\
\text { in } \mu^{2}\end{array}$ & $\begin{array}{l}\text { Specimen, furnace } \\
\text { cooled }\end{array}$ & $\begin{array}{c}\text { Average } \\
\text { tempera- } \\
\text { ture of } \\
\text { heating }\end{array}$ & $\begin{array}{l}\text { Number } \\
\text { of grains } \\
\text { per mm² }\end{array}$ & $\begin{array}{c}\text { Area of } \\
\text { grain } \\
\text { in } \mu^{2}\end{array}$ \\
\hline & ${ }^{\circ} \mathrm{C}$ & & & & ${ }^{\circ} \mathrm{C}$ & & \\
\hline $\mathbf{A}-1 \ldots$ & 674 & 1690 & 590 & A-11... & 674 & 1800 & 550 \\
\hline A-2... & 762 & 2330 & 430 & A-22... & 762 & (a) & (a) \\
\hline A-3.... & 849 & 2010 & 500 & A-33... & 849 & 930 & 1070 \\
\hline$A-4 \ldots$. & 953 & 1330 & 750 & A-44... & 953 & $(a)$ & (a) \\
\hline $2-A-4$. & 974 & 580 & 1930 & $2-A-44$ & 974 & 92 & 10920 \\
\hline $1-A-5$. & 1024 & 380 & 2610 & $1-\mathrm{A}-55$ & 1024 & 66 & 15200 \\
\hline A-5... & 1112 & (a) & (a) & A-55... & 1112 & 32 & 31640 \\
\hline B-1... & 674 & 2620 & 380 & B-11... & 674 & 2857 & 350 \\
\hline B-2... & 762 & $(a)$ & (a) & B-22... & 762 & $(a)$ & (a) \\
\hline B-3.... & 849 & 1520 & 660 & B-33.... & 849 & 360 & 2810 \\
\hline B-4..... & 953 & (a) & (a) & B-44.... & 953 & 290 & 3410 \\
\hline $2-B-4 .$. & 974 & (a) & (a) & $2-B-44$ & 974 & 220 & 4490 \\
\hline $1-B-5 .$. & 1024 & (a) & $(a)$ & 1-B-55.. & 1024 & 168 & 5950 \\
\hline B-5.... & 1112 & (a) & (a) & B-55........ & 1112 & 144 & 6940 \\
\hline C-1.. & 674 & $(a)$ & $(a)$ & C-11... & 674 & (a) & (a) \\
\hline $\mathrm{C}-2 \ldots$. & 762 & (a) & (a) & $\mathrm{C}-22 \ldots$ & 762 & (a) & (a) \\
\hline $\mathrm{C}-3 \ldots$. & 849 & (a) & (a) & C-33..... & 849 & (a) & (a) \\
\hline$C-4 \ldots .$. & 953 & 410 & 2410 & C-44..... & 953 & (a) & (a) \\
\hline $2-C-4 .$. & 974 & 22 & $45 \quad 250$ & 2-C-44.. & 974 & 19 & 52630 \\
\hline $1-C-5 \ldots$. & 1024 & 20 & 49880 & $1-C-55 \ldots .$. & 1024 & (a) & (a) \\
\hline C-5...... & 1112 & 12. 8 & 77820 & C-55........ & 1112 & 7.5 & 104850 \\
\hline D-1.. & 674 & (a) & (a) & D-11... & 674 & $(a)$ & (a) \\
\hline $\mathrm{D}-2 \ldots$ & 762 & (a) & (a) & $\mathrm{D}-22 \ldots \ldots \ldots$ & 762 & (a) & (a) \\
\hline D-3.... & $8+9$ & (a) & (a) & D-33........... & 849 & (a) & (a) \\
\hline D-4... & 953 & (a) & (a) & D-44.... & 953 & (a) & (a) \\
\hline $2-D-4 \ldots$ & 974 & (a) & (a) & $2-D-44 \ldots$ & 974 & $(a)$ & (a) \\
\hline $1-D-5 \ldots$ & 1024 & 21 & 47620 & $1-D-55 \ldots$. & 1024 & 23 & 42 a? \\
\hline D-5... & 1112 & 12.5 & 80000 & D-55....... & 1112 & 11 & 87910 \\
\hline$E-1 \ldots$ & 674 & $(a)$ & (a) & E-11 ... & 674 & (a) & (a.) \\
\hline E-2... & 762 & (a) & (a) & $E-22 \ldots \ldots$. & 762 & (a) & (a) \\
\hline E-3... & 849 & (a) & (a) & E-33.... & 849 & (a) & $(a)$ \\
\hline E-4... & 953 & $(a)$ & (a) & E-44..... & 953 & 116 & $866 n$ \\
\hline $2-E-4 \ldots$ & 974 & (a) & (a) & $2-E-44 \ldots$ & 974 & 49 & 20410 \\
\hline $1-E-5 \ldots$ & 1024 & (a) & (a) & $1-E-55 \ldots$ & 1024 & 34 & 29411 \\
\hline E-5... & 1112 & $(a)$ & (a) & E-55 .... & 1112 & 20 & 49140 \\
\hline
\end{tabular}

$a$ No satisfactory count could be made.

On account of this uncertainty, therefore, there are given in Figs. I to I I, inclusive, typical micrographs of the specimens to show the structural condition which resulted from the treatment which the material received. They also illustrate the difficulties encountered in making an accurate grain-size determination, as well as the structural features other than grain size which affect the properties of the material. In Figs. I 2 and I 3 are given typical micrographs of the steels heated at the highest tempera- 
ture, highly enough magnified to demonstrate the effect of the rate of cooling upon the structure of the steel; that is, the inner structure of the grains.

The specimens of series $\mathrm{I}(\mathrm{A}-\mathrm{I}, \ldots \mathrm{E}-\mathrm{I}$ and $\mathrm{A}-\mathrm{I} \mathrm{I} \ldots$ $\mathrm{E}-\mathrm{I}$ I), which were heated to a temperature slightly below the $\mathrm{Ac}_{1}$ transformation retain the original grain size of the materiai. The specimens heated just above this transformation show a decrease in grain size (in those specimens in which the grains are clearly defined). This is best seen in the materials which were cooled in the air. In all of the five types of steels the increase in grain size is very slight for the lower temperatures. Not until the $\mathrm{Ac}_{3}$ transformation has occurred and the steel is in the gamma phase, is the increase in the grain size very marked. In some of the steels this occurs upon heating when the temperature of the $\mathrm{Ac}_{3}$ transformation is reached. In two, however ( 0.46 and 0.70 per cent carbon), no appreciable increase in grain size occurs until the temperature is considerably above that of the $\mathrm{Ac}_{3}$ transformation (approximately $2 \mathrm{OO}^{\circ}$ ). The marked increase for these specimens occurs also within a relatively very narrow range of temperature, 950 to $975^{\circ} \mathrm{C}$, approximately.

In Fig. I 4 there is given a portion of the iron-carbon constitutional diagram, in which has been indicated, for purposes of reference, the range of temperature in which the grain size increases most rapidly in each of the steels used.

\section{HARDNESS DETERMINATIONS}

Two methods were used for determining the mechanical hardness of the material. The specimen used for the determination of the microstructure was large enough ( 1 by $\mathrm{I} / 2$ inches face) to permit all the determinations of hardness to be made upon the one piece. The two forms of the Brinell hardness-testing set used will be referred to as the "standard" and the "micro-Brinell" set, respectively. For the former the usual hydraulic type was used, and a load of $500 \mathrm{~kg}$ was applied to the specimen by means of a ball ro $\mathrm{mm}$ in diameter for 30 seconds. For the second set of determinations a small "dead-weight" type of Brinell apparatus was used. The instrument (Fig. I5), which was developed by the Ordnance Department of the United States Army, was loaned for the purpose. A load of $\mathrm{I}_{5} \mathrm{~kg}$ for 30 seconds upon a ball one-sixteenth inch in diameter was used. The details of construction and manipulation have been described elsewhere. ${ }^{10}$

${ }^{10}$ S. I. Goodale and R. M. Banks, Development of Brinell Harness Tests on Thin Sheet Brass, Proc. A. S. T. M., 19, Pl. II, p. 757; 1919. 


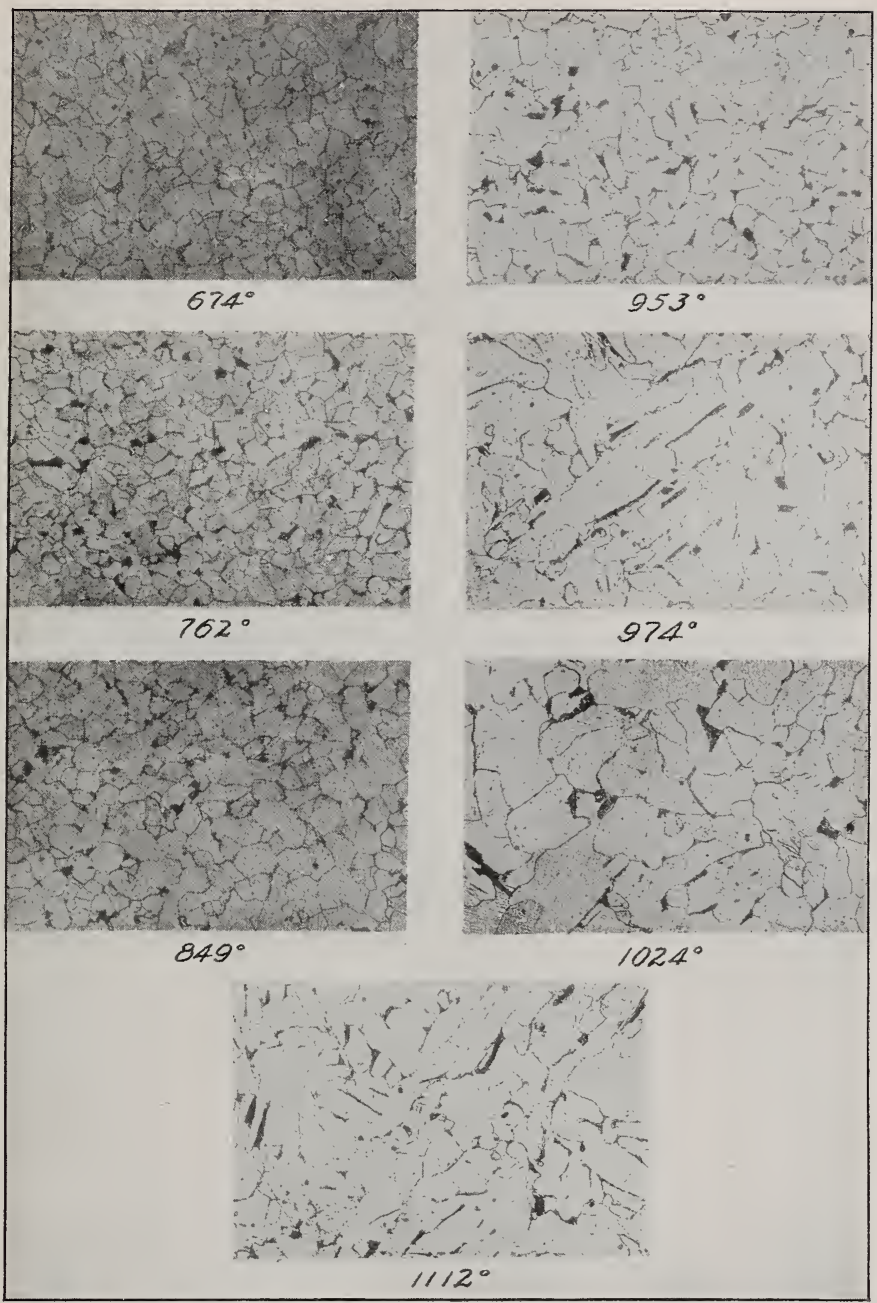

FIG. I.-Microstructure of 0.07 per cent carbon steel (steel A) after annealing and cooling in air; $\times 75$ (reduced from $\times 100)$

Each specimen was heated six hours at temperature $\left({ }^{\circ} \mathrm{C}\right)$ shown. Etched with 2 per cent alcoholic nitric acid

$1988^{\circ}-20-2$ 


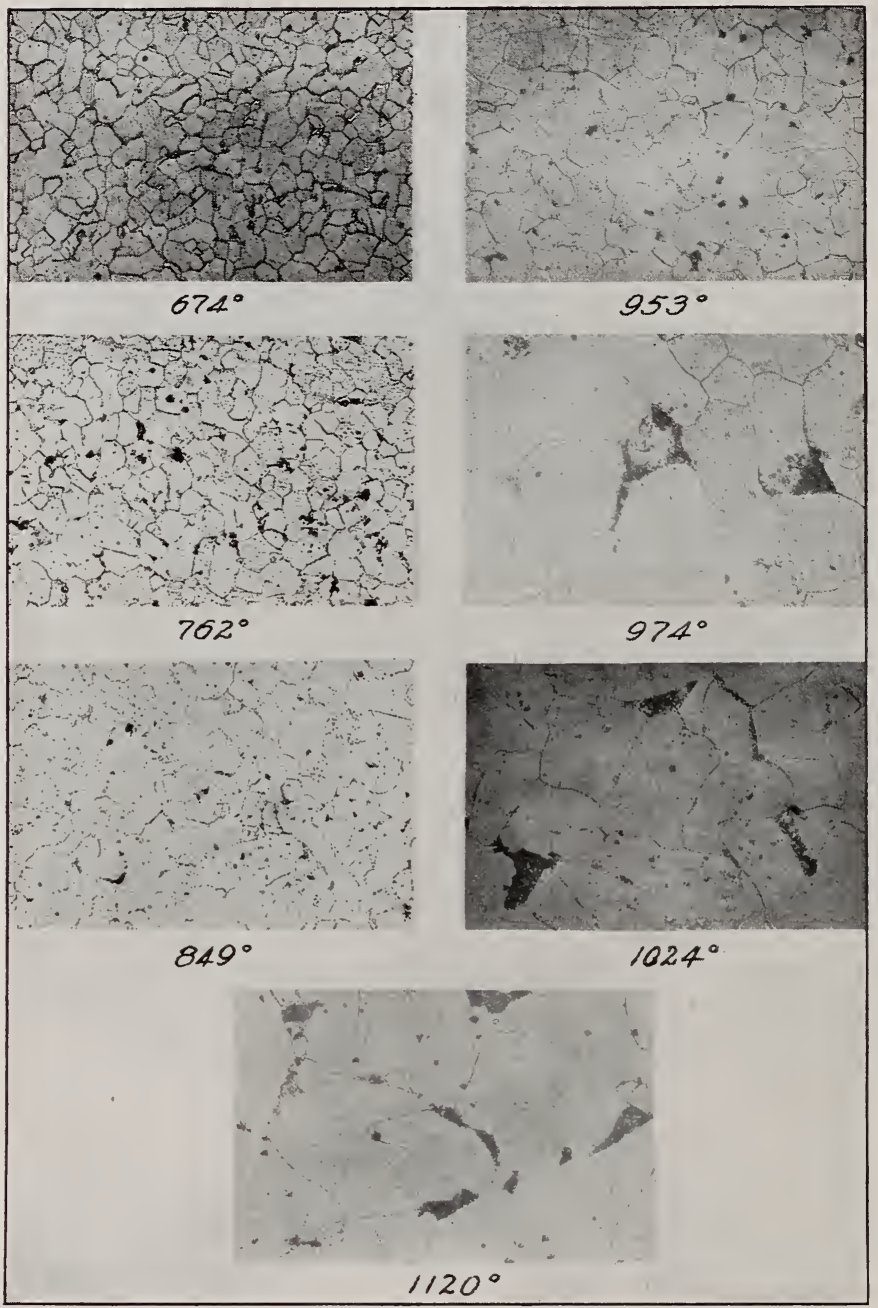

FIG. 2.-Microstructure of 0.07 per cent carbon steel (steel A) after annealing and cooling in the furnace; $\times 75$ (reduced from $\times I O O)$

Each specimen was heated six hours at temperature $\left({ }^{\circ} \mathrm{C}\right)$ shown. Etched with 2 per cent alcoholic nitric acid 


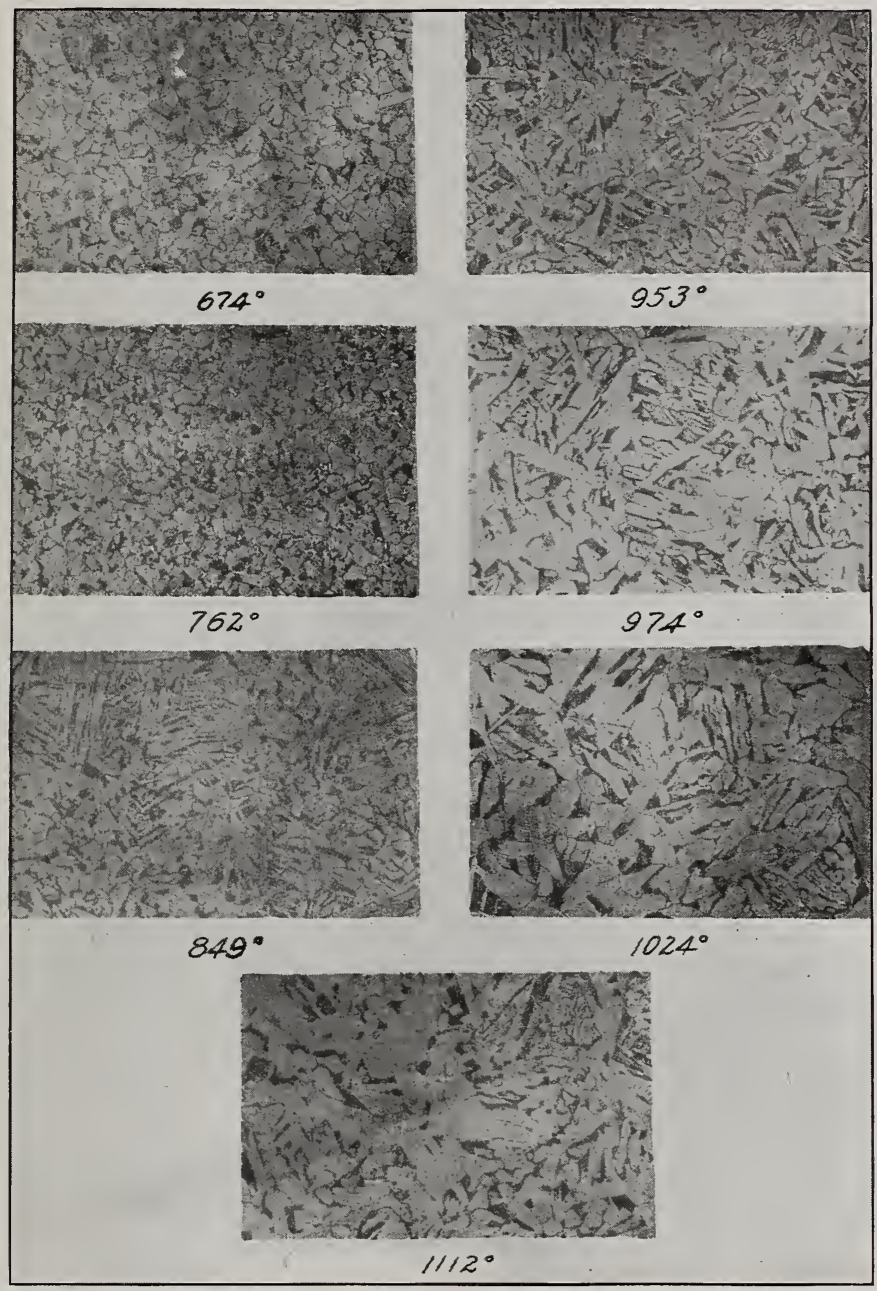

FIG. 3.-Microstructure of o.I9 per cent carbon steel (steel B) after annealing and cooling in air; $\times 75$ (reduced from $\times$ IOO)

Each specimen was heated six hours at temperature $\left({ }^{\circ} \mathrm{C}\right)$ shown. Etched with 2 per cent alcoholic nitric acid 


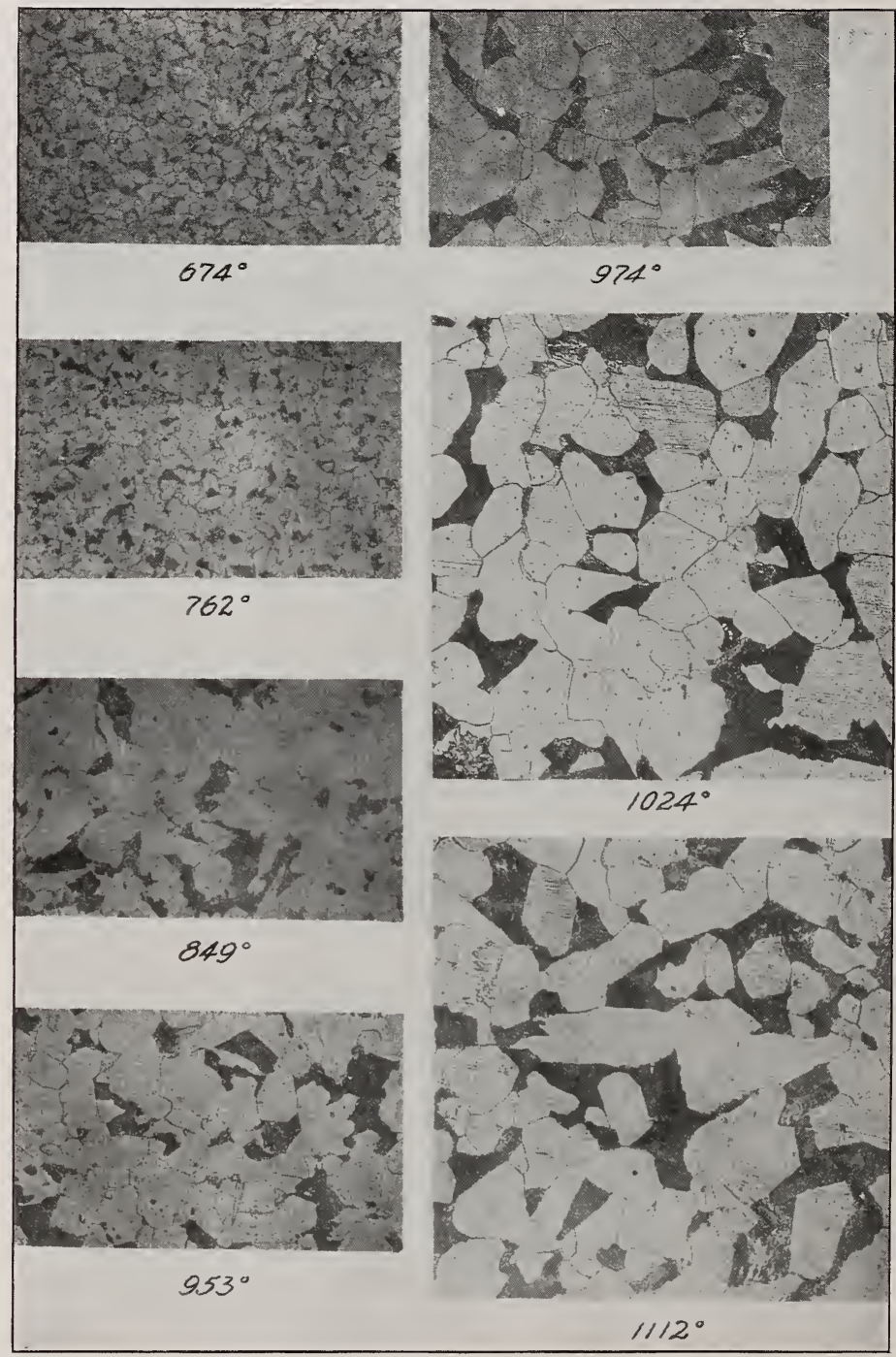

Fig. 4.-Microstructure of O.I9 per cent carbon steel (steel B) after annealing and cooling in furnace; $\times 75$ (reduced from $\times$ TOO)

Each specimen was heated six hours at temperature $\left({ }^{\circ} \mathrm{C}\right)$ shown. Etched with 2 per cent alcoholic nitric acid 


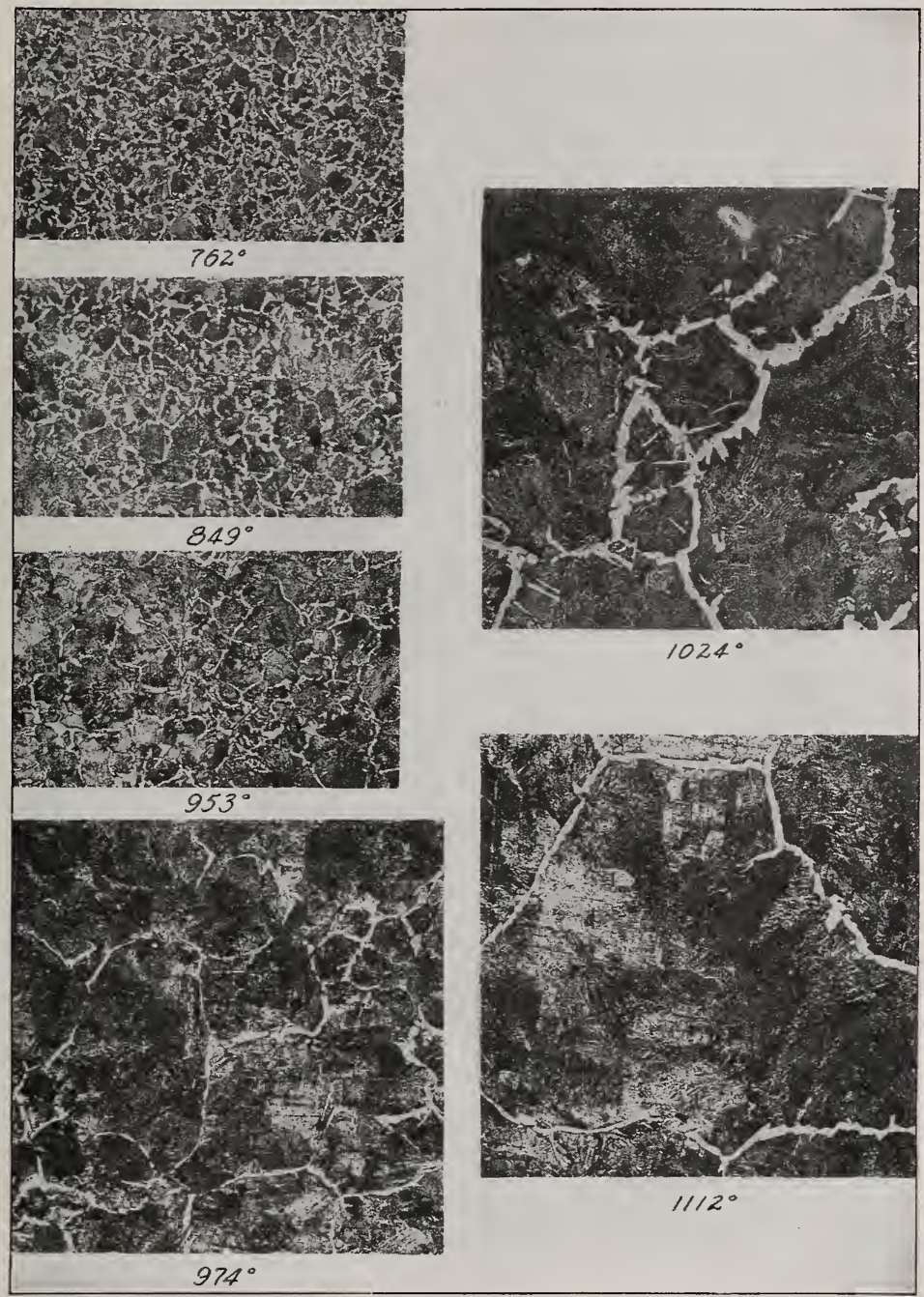

FIG. 5.-Microstructure of 0.46 per cent carbon steel (steel $C$ ) after annealing and cooling in air; $\times 75$ (reduced from $\times I O O)$

Each specimen was heated six hours at temperature $\left({ }^{\circ} \mathrm{C}\right)$ shown. Etched with 2 per cent aicoholic nitric acid 


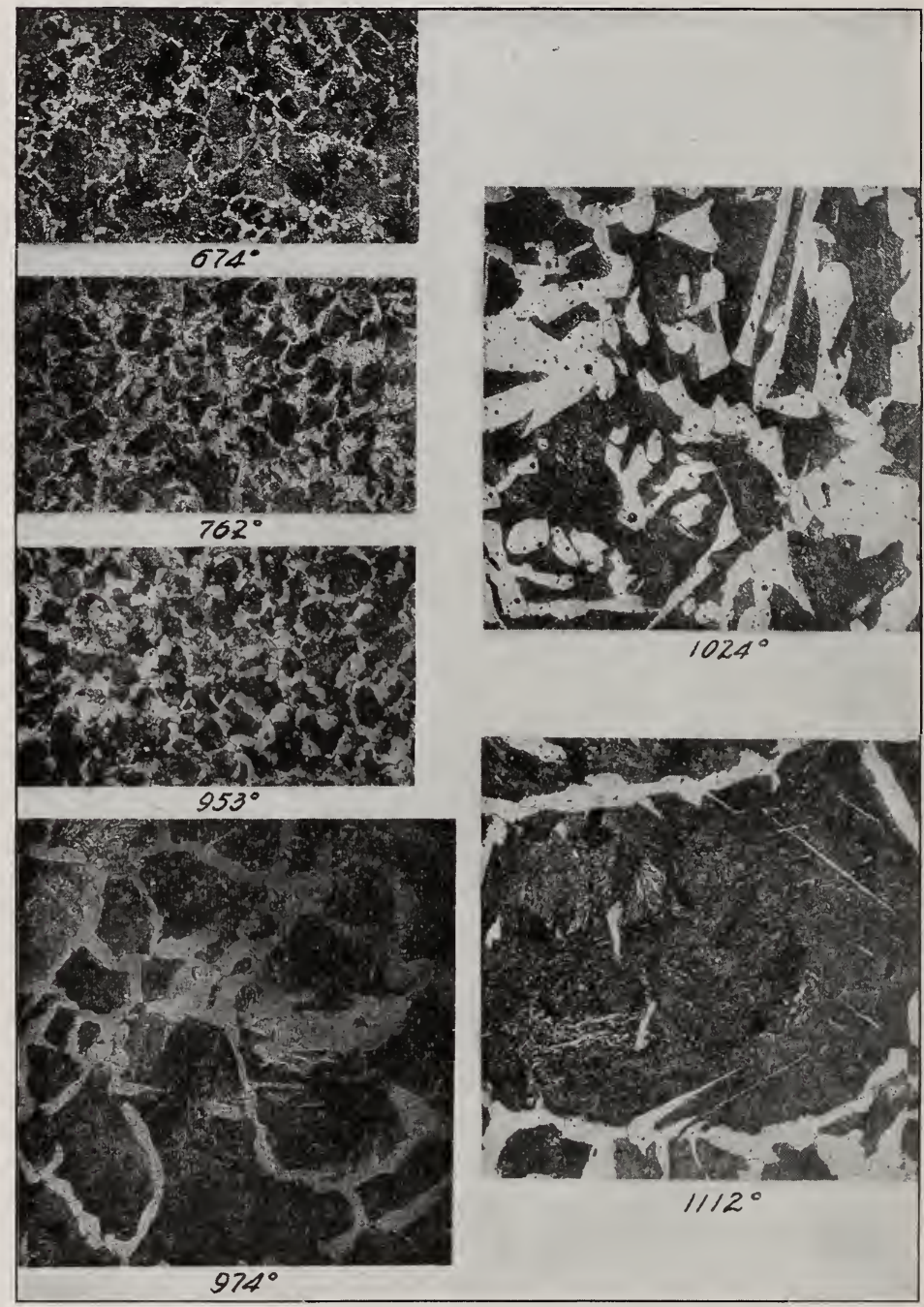

FIG. 6.-Microstructure of 0.46 per cent carbon steel (steel $C$ ) after annealing and cooling in furnace; $\times 75$ (reduced from $\times 100)$

Each specimen was heated six hours at temperature $\left({ }^{\circ} \mathrm{C}\right)$ shown. Eitched with 2 per cent alcoholic nitric acid 


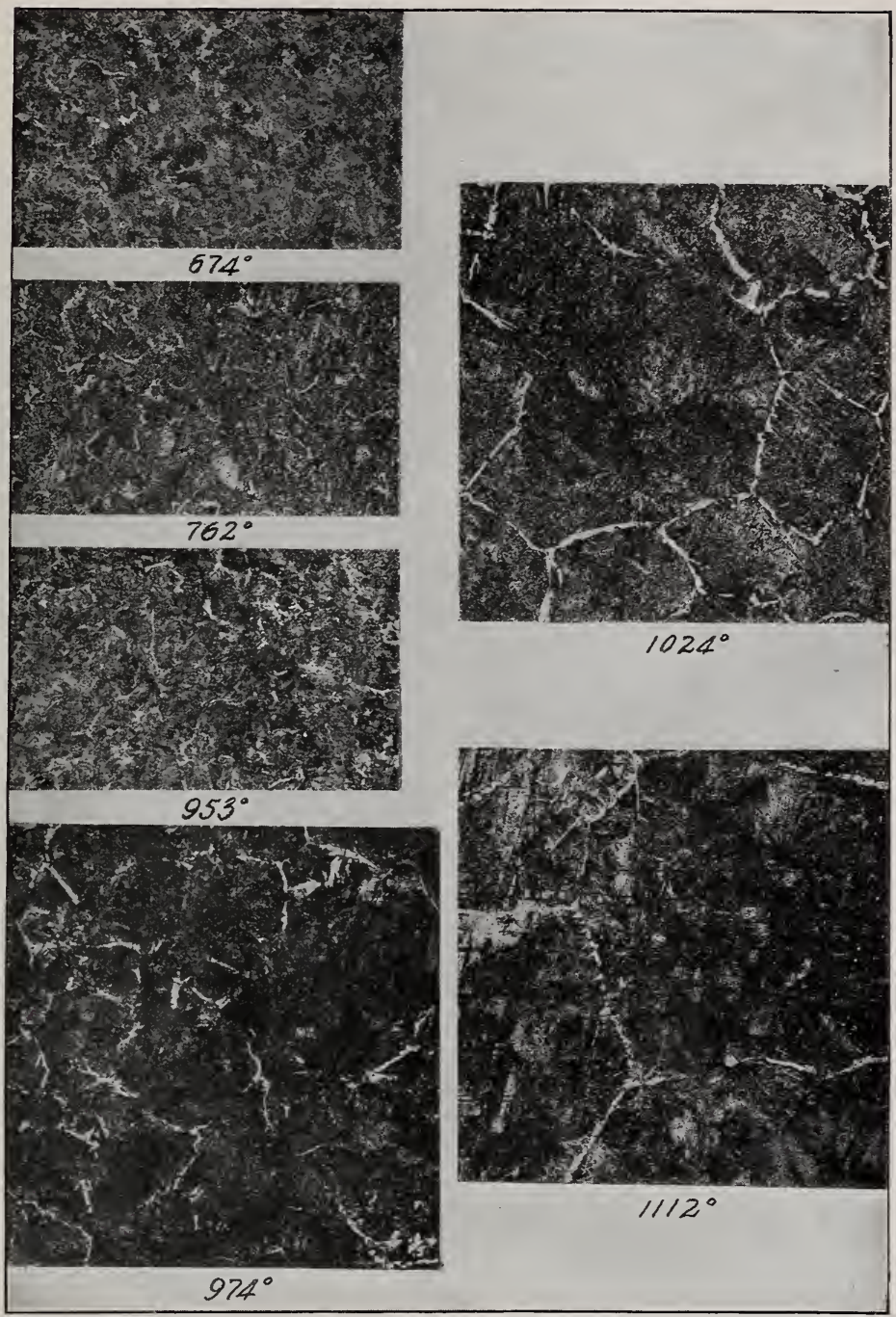

FIG. 7.-Microstructure of 0.70 per cent carbon steel (steel $D)$ after annealing and cooling in air; $\times 75$ (reduced from $\times 100)$

Each specimen was heated six hours at temperature $\left({ }^{\circ} \mathrm{C}\right)$ shown. Eitched with 2 per cent alcoholic nitric acid 


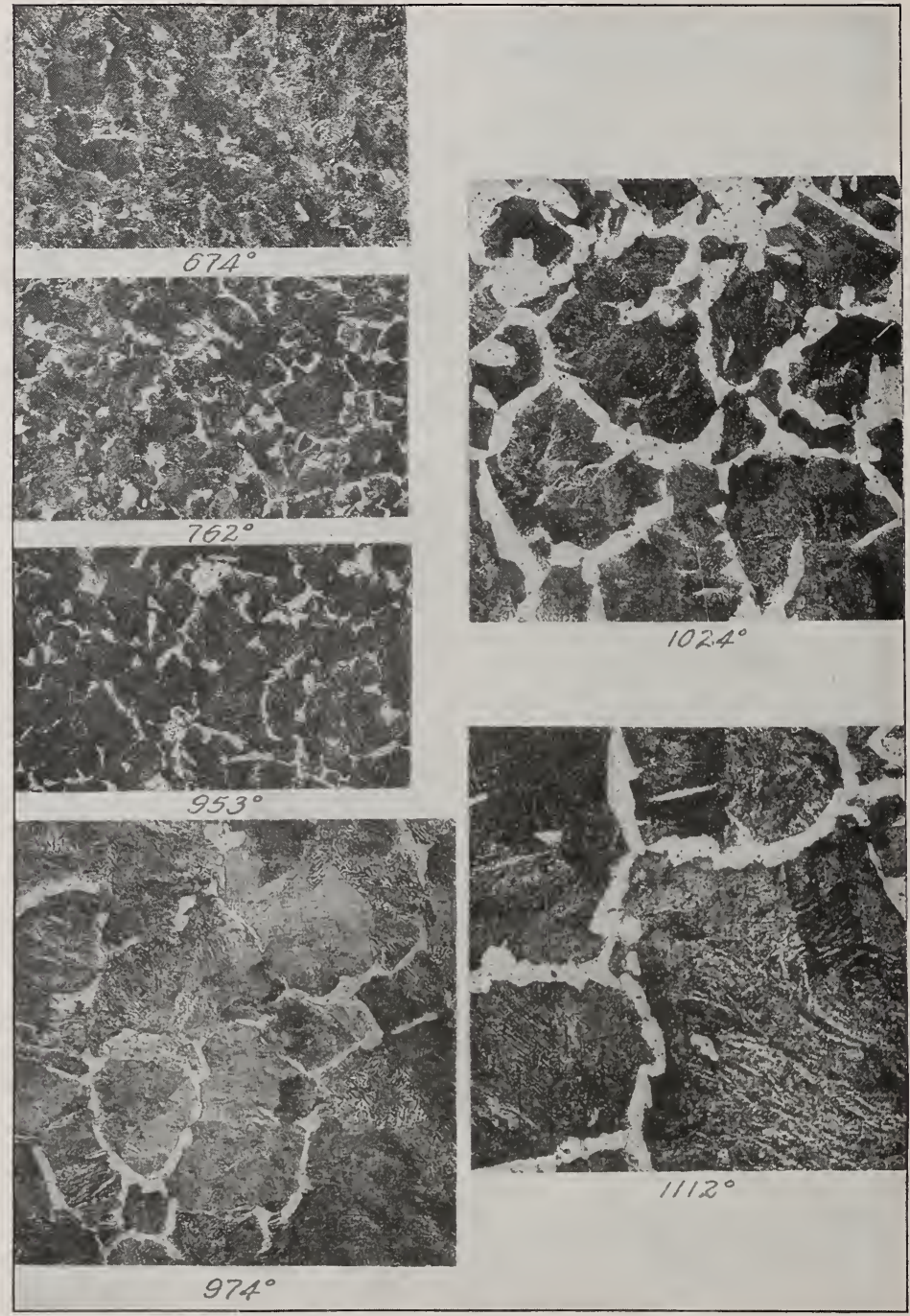

FIG. 8.-Microstructure of 0.70 per cent carbon steel (steel D) after annealing and cooling in furnace; $\times 75$ (reduced from $\times 100)$

Each specimen was heated six hours at temperature $\left({ }^{\circ} \mathrm{C}\right)$ shown. Eitched with 2 per cent alcoholic nitric acid 


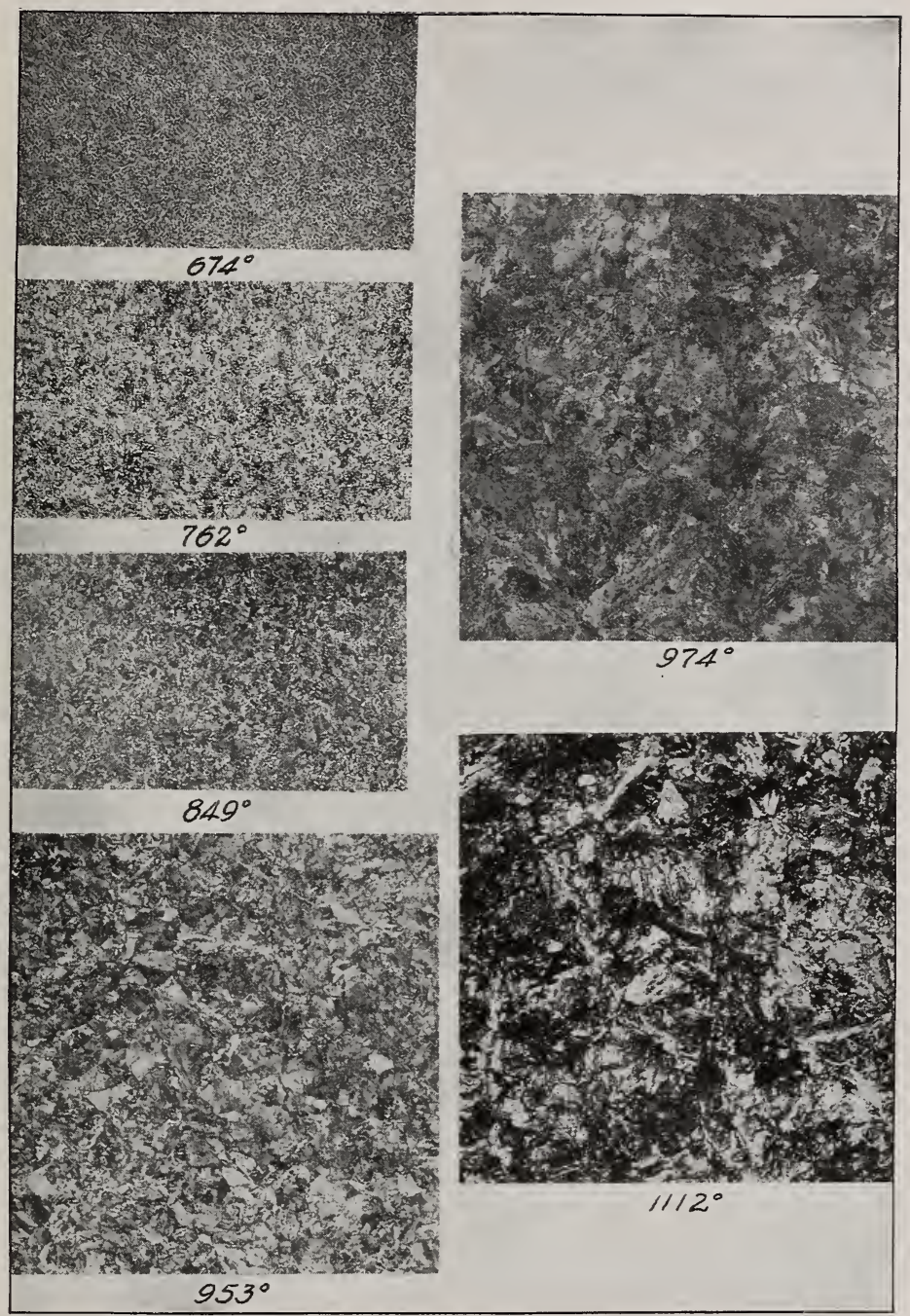

FIG. 9.-Microstructure of I.I2 per cent carbon steel (steel E) after annealing and cooling in air; $\times 75$ (reduced from $\times 100)$

Each specimen was heated six hours at temperature $\left({ }^{\circ} \mathrm{C}\right)$ shown. Etched with 2 per cent alcoholic nitric acid

$1988^{\circ}-20-3$ 


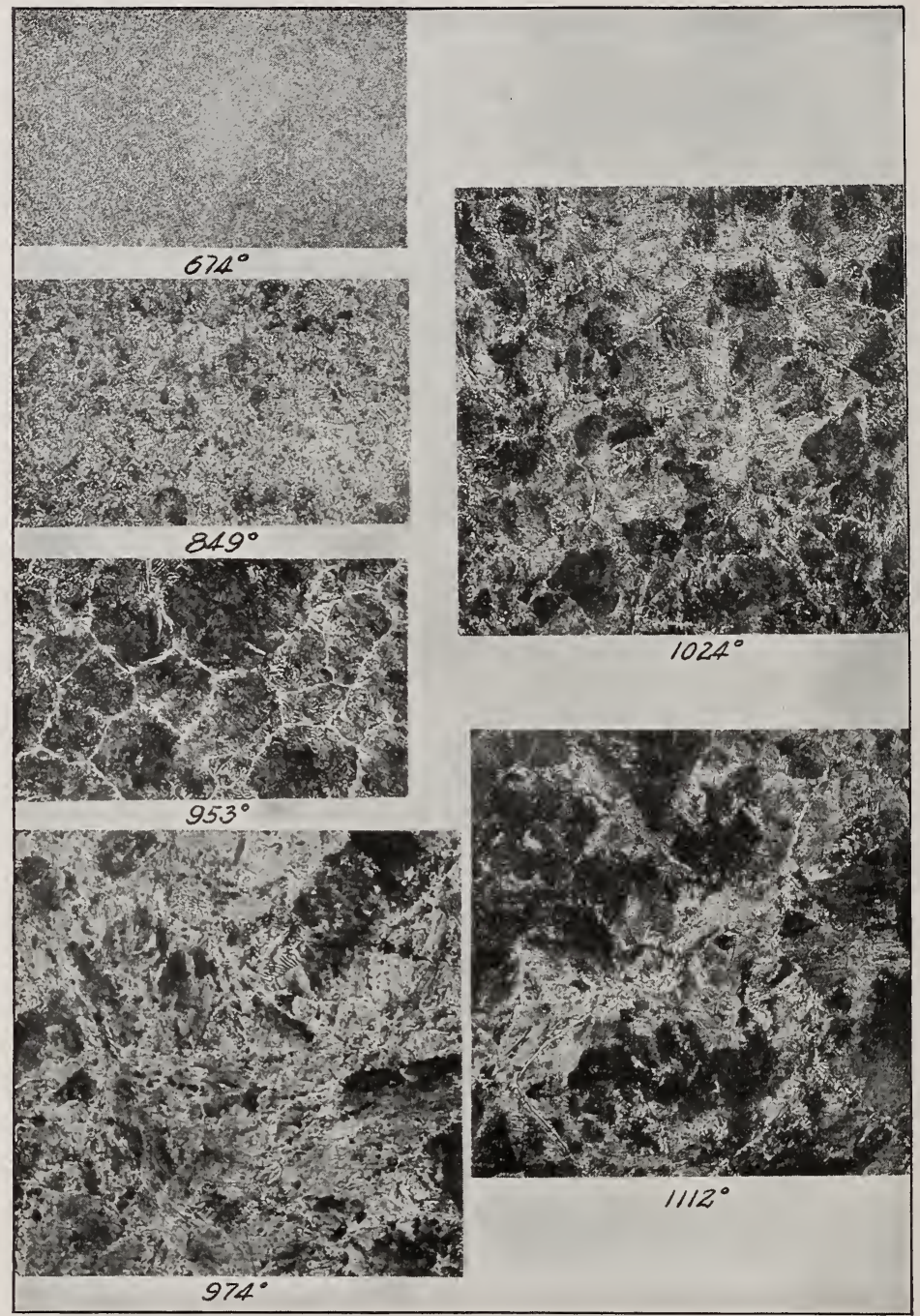

FIG. IO.-Microstructure of I.I2 per cent carbon steel (steel E) after annealing and cooling in furnace; $\times 75$ (reduced from $\times I O O)$

Each specimen was heated six hours at temperature $\left({ }^{\circ} \mathrm{C}\right)$ shown. Etched with 2 per cent alcoholic nitric acid. 


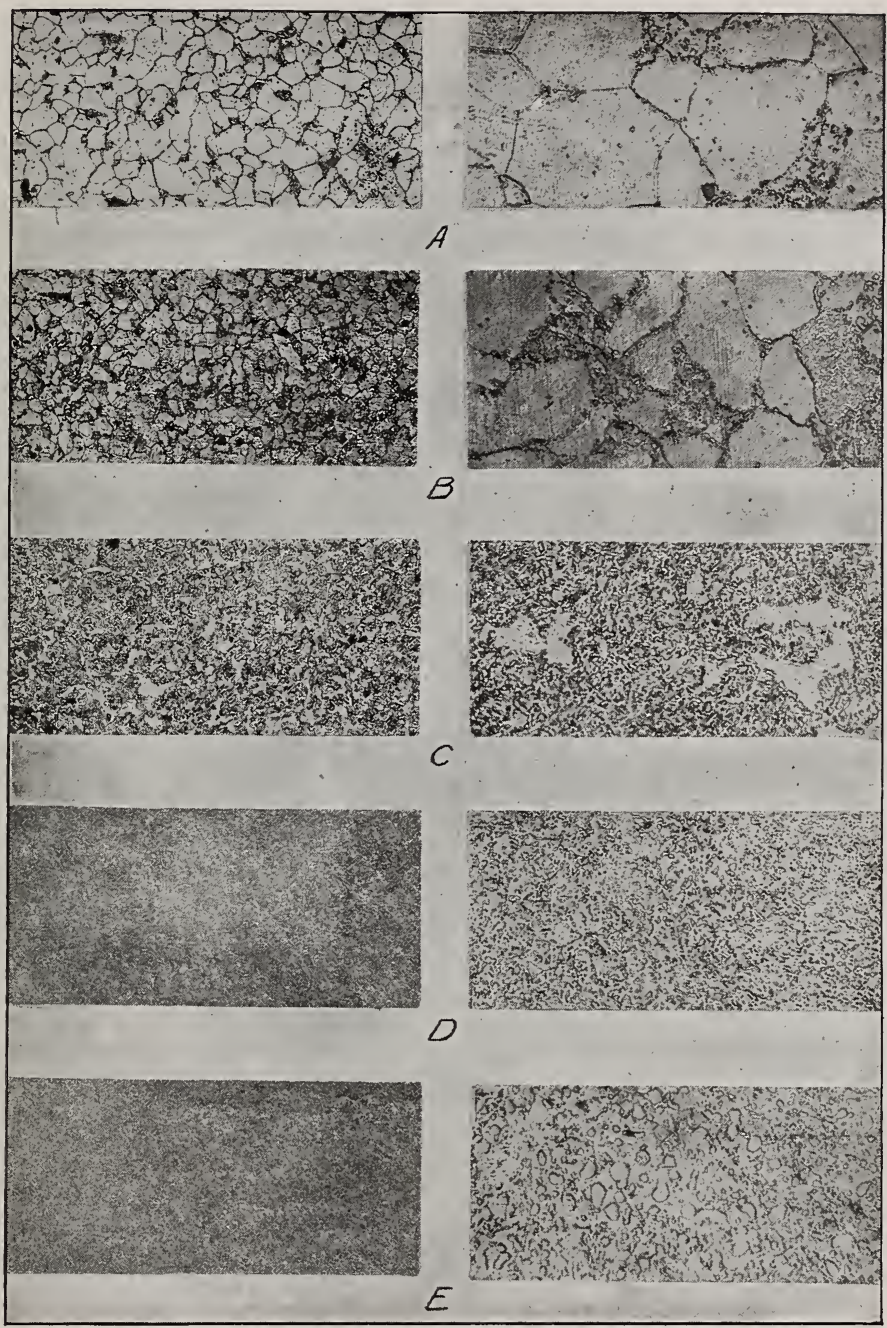

FIG. II.-Microstructure of the five types of steel used, after maximum grain refinement. Magnification of micrographs at left, $\times 75$ (reduced from $\times$ IOO); at right $\times 375$ (reduced from $\times 500)$

A specimen of each of the steels was quenched in water after being heated 35 minutes at $754^{\circ} \mathrm{C}$, it was then heated for 6 hours at $674^{\circ} \mathrm{C}$. Etched with 2 per cent alcoholic nitric acid 
The Brinell hardness number was calculated by means of the ordinary formula:

$$
N=\frac{\text { Pressure }}{\text { area of spherical indentation }}=\frac{P}{\pi t D}
$$

in which $t=1 / 2\left(D-\sqrt{D^{2}-d^{2}}\right), D$ and $d$ being the diameter of the ball and of its indentation, respectively. Although the loads

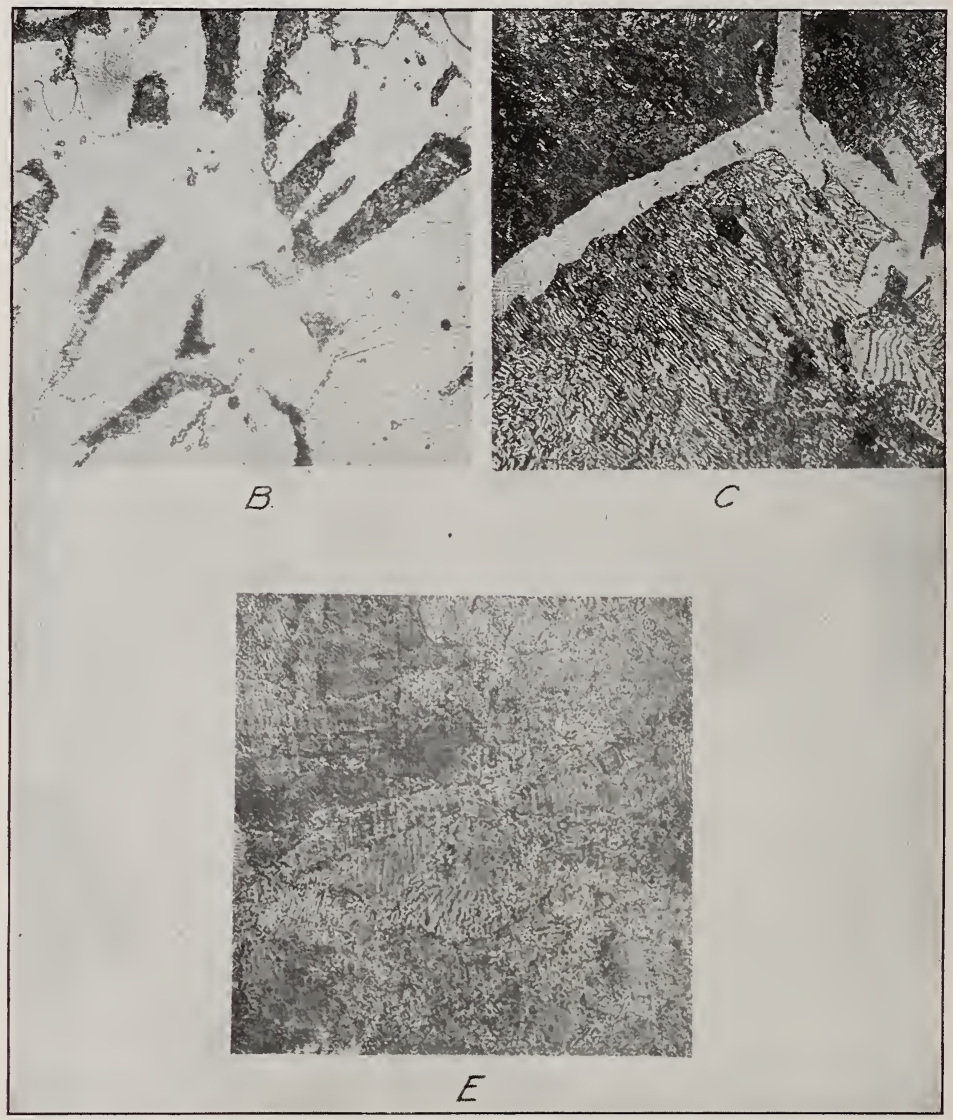

FIG. I2.-Effect of rate of cooling upon the structure of steels $B, C$, and $E$; $\times 375$ (reduced from $\times 500)$

These were cooled in air after a period of heating of six hours at $1112^{\circ} \mathrm{C}$. Eitched with 2 per cent alcoholic nitric acid. (Compare Fig. 1.3)

used for the two Brinell sets were not in exactly the same ratio as the sizes of the two balls, the hardness numbers obtained by the two are in very fair agreement.

The results of the determinations of hardness are summarized in Tables 4 and 5 . The comparative hardness of the various 
steels in different conditions of structure are best shown, however, in the graphical results of Figs. I6 to 19, inclusive. In plotting the diagrams the temperatures at which the various steels were

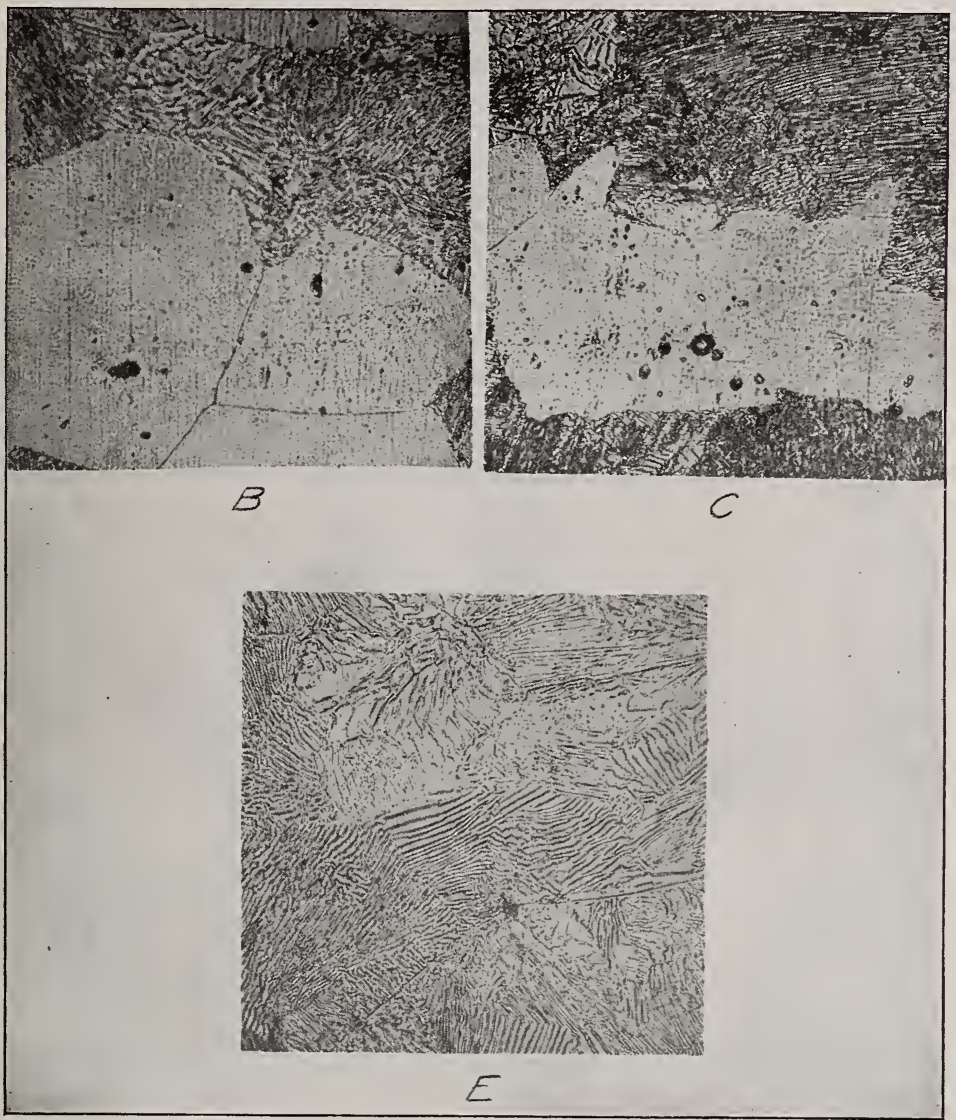

FIG. I3.-Effect of rate of cooling upon the structure of steels $B, C$, and $E$; $\times 375$ (reduced from $\times 500)$

These were cooled in the furnace after a period of heating of six hours at $1112^{\circ} \mathrm{C}$. Etched with 2 per cent alcoholic nitric acid. (Compare Fig. 12.) Note the character of the pearlite and the width of the ferrite envelopes)

treated in order to develop the different grain size, rather than the numerical measures of the grain-size determinations, were used as abscissas. 


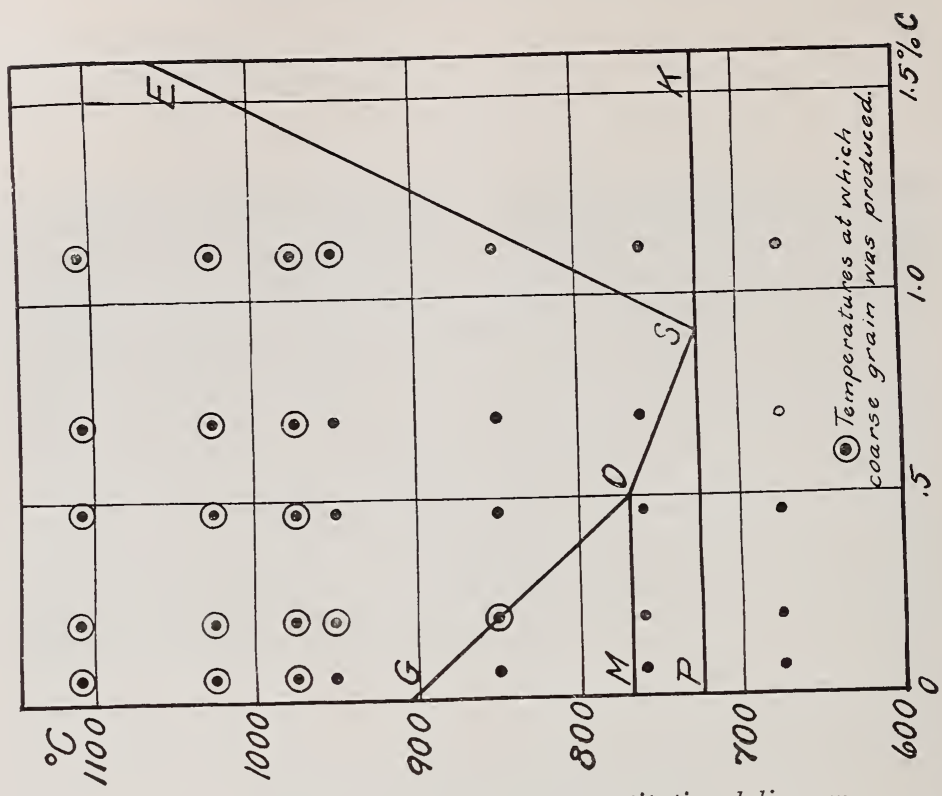

FIG. I4.-Portion of the iron-carbon constitutional diagram

The temperature range in which pronounced grain growth of the various steels (Table $\mathrm{I}$ ) occurred in a period of S1x hours has been indicated

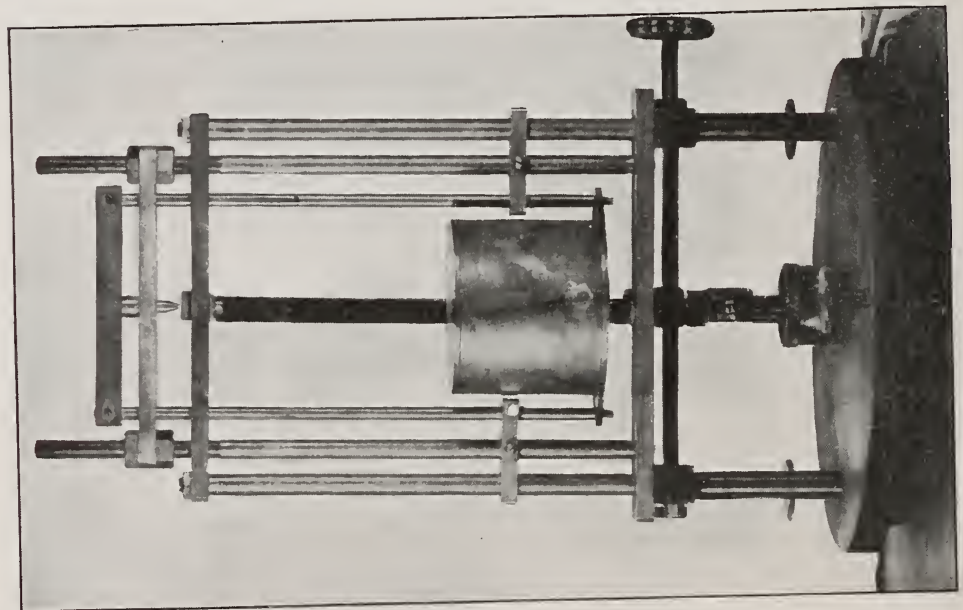

FIG. 15.-Apparatus for obtaining micro-Brinell hardness number 
TABLE 4.-Micro-Brinell Hardness Numbers of Air-Cooled and Furnace-Cooled Specimens $a$

\begin{tabular}{|c|c|c|c|c|c|c|c|}
\hline \multirow{2}{*}{$\begin{array}{l}\text { Specimen } \\
\text { air cooled }\end{array}$} & \multicolumn{3}{|c|}{ Hardness number } & \multirow{2}{*}{$\begin{array}{c}\text { Specimen } \\
\text { furnace cooled }\end{array}$} & \multicolumn{3}{|c|}{ Hardness number } \\
\hline & Maximum & Minimum & Average $b$ & & Maximum & Minimum & Average $b$ \\
\hline$A-1 \ldots \ldots$. & 83 & 76 & 79 & A-11 .............. & 76 & 69 & 71 \\
\hline$A-2 \ldots$ & 81 & 77 & 78 & $A-22 \ldots .$. & 75 & 71 & 73 \\
\hline$A-3 \ldots$. & 88 & 82 & 85 & $A-33 \ldots \ldots$ & 83 & 77 & 81 \\
\hline $1-4 \ldots$ & 83 & 81 & 82 & A-44, $\ldots$ & 73 & 70 & 71 \\
\hline $2-\mathrm{A}-4 \ldots$ & 88 & $8 !$ & 86 & $2-\mathrm{A}-44 \ldots \ldots$ & 83 & 76 & 78 \\
\hline $1-\mathrm{A}-5 \ldots \ldots$ & 74 & 71 & 72 & $1-A-55 \ldots \ldots$ & 70 & 61 & 65 \\
\hline$A-5 \ldots$ & 84 & 81 & 82 & A-55 .............. & 70 & 66 & 68 \\
\hline $\mathrm{B}-1 \ldots$ & 91 & 86 & 88 & B-11 .............. & 91 & 88 & 89 \\
\hline B-2 . . . . . . & 107 & 99 & 103 & B-22.............. & 87 & 84 & 85 \\
\hline$B-3 \ldots$. & 107 & 103 & 105 & B-33................ & 87 & 83 & 85 \\
\hline$B-4 \ldots$. & 106 & 95 & 102 & B-44............... & 85 & 83 & 84 \\
\hline $2-B-4 \ldots$ & 105 & 101 & 103 & $2-B-44 \ldots \ldots$ & 93 & 81 & 87 \\
\hline $1-B-5 \ldots$. & 89 & 85 & 87 & $1-B-55 \ldots \ldots$ & 79 & 72 & 75 \\
\hline B-5.... & 93 & 88 & 90 & B-55................ & 80 & 75 & 77 \\
\hline $\mathrm{C}-1 \ldots$ & 157 & 144 & 153 & $\mathrm{C}-11 \ldots \ldots$ & 150 & 148 & 152 \\
\hline $\mathrm{C}-2 \ldots \ldots \ldots$ & 164 & 161 & 162 & $\mathrm{C}-22 \ldots .$. & 139 & 132 & 136 \\
\hline $\mathrm{C}-3 \ldots$. & 174 & 170 & 173 & C-33................... & 145 & 140 & 143 \\
\hline $\mathrm{C}-4 \ldots$. & 180 & 172 & 177 & C-44.................. & 146 & 142 & 144 \\
\hline $2-C-4 \ldots$. & 191 & 180 & 185 & $2-C-44 \ldots \ldots$ & 164 & 157 & 161 \\
\hline $1-C-5 \ldots$. & 167 & 161 & 164 & $1-C-55 \ldots$. & 135 & 130 & 132 \\
\hline C-5............... & 185 & 165 & 177 & $\mathrm{C}-55 \ldots \ldots$ & 148 & 138 & 146 \\
\hline D-1........ & 171 & 166 & 169 & D-11............... & 167 & 160 & 164 \\
\hline$D-2 \ldots .$. & 198 & 186 & 194 & $D-22 \ldots \ldots$ & 164 & 156 & 160 \\
\hline$D-3 \ldots \ldots . . . .$. & 202 & 194 & 199 & $\mathrm{D}-33 \ldots \ldots$ & 175 & 166 & 171 \\
\hline$D-4 \ldots \ldots . .$. & 204 & 197 & 201 & 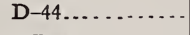 & 165 & 161 & 164 \\
\hline $2-D-4 \ldots \ldots$. & 219 & 208 & 213 & $2-D-44 \ldots \ldots$ & 170 & 148 & 159 \\
\hline $1-D-5 \ldots$. & 202 & 191 & 193 & $1-\mathrm{D}-55 \ldots$. & 163 & 152 & 155 \\
\hline D-5......... & 208 & 195 & 200 & D-55.............. & 170 & 163 & 165 \\
\hline $\mathbf{E}-1 \ldots$ & 155 & 148 & 151 & E-11 .............. & 140 & 135 & 137 \\
\hline $\mathrm{E}-2 \ldots$ & 218 & 208 & 212 & E-22................. & 165 & 162 & 164 \\
\hline $\mathrm{E}-3 \ldots$. & 228 & 220 & 225 & $\mathrm{E}-33 \ldots \ldots$ & 182 & 179 & 180 \\
\hline $\mathrm{E}-4 \ldots$. & 267 & 256 & 259 & E-44............... & 194 & 186 & 190 \\
\hline $2-E-4 \ldots .$. & 279 & 262 & 270 & $2-E-44 \ldots \ldots \ldots$ & 191 & 185 & 189 \\
\hline $1-\mathbf{E}-5 \ldots \ldots$ & 240 & 231 & 236 & $1-\mathrm{E}-55 \ldots \ldots$ & 191 & 180 & 184 \\
\hline E-5 ... & 264 & 257 & 260 & E-55 . . . . & 195 & 191 & 193 \\
\hline & & & & A-66........ & 75 & 74 & 74 \\
\hline & & & & B-66.................. & 95 & 91 & 93 \\
\hline & & & & $\mathrm{C}-66 \ldots$. & 150 & 144 & 147 \\
\hline & & & & D-66................... & 164 & 159 & 162 \\
\hline$\cdots$ & & & $\ldots$ & E-66................ & 156 & 153 & 155 \\
\hline
\end{tabular}

$a_{\text {I5 }} \mathrm{kg}$ load applied to one-sixteenth-inch ball for 30 seconds.

$b$ Average of 6 determinations. 
TABLE 5.-Standard Brinell Hardness Numbers $a$

\begin{tabular}{|c|c|c|c|c|c|c|c|}
\hline $\begin{array}{l}\text { Specimen, } \\
\text { air cooled }\end{array}$ & $\begin{array}{c}\text { Hard- } \\
\text { ness } \\
\text { number } b\end{array}$ & $\begin{array}{l}\text { Specimen, } \\
\text { furnace cooled }\end{array}$ & $\begin{array}{c}\text { Hard- } \\
\text { ness } \\
\text { number } b\end{array}$ & $\begin{array}{l}\text { Specimen, } \\
\text { air cocled }\end{array}$ & $\begin{array}{c}\text { Hard- } \\
\text { ness } \\
\text { number } b\end{array}$ & $\begin{array}{l}\text { Specimen, } \\
\text { furnace cooled }\end{array}$ & $\begin{array}{c}\text { Hard- } \\
\text { ness } \\
\text { number } b\end{array}$ \\
\hline$A-1 \ldots$. & 75 & A-11.... & 73 & D-1... & 149 & D-11.. & 151 \\
\hline$A-2 \ldots \ldots$. & 78 & $A-22 \ldots \ldots$ & 72 & $\mathrm{D}-2 \ldots \ldots$ & 182 & D-22....... & 130 \\
\hline A-3........ & 81 & A-33....... & 71 & $D-3 \ldots \ldots$ & 185 & D-33... & 146 \\
\hline A-4.... & 81 & A-44.... & 69 & D-4.... & 188 & D-44... & 149 \\
\hline $2-A-4 \ldots$. & 81 & $2-A-44 \ldots \ldots$ & 65 & $2-D-4 \ldots \ldots$ & 198 & $2-D-44 \ldots$ & 153 \\
\hline $1-A-5 \ldots . .$. & 72 & $1-A-55 \ldots .$. & 62 & $1-D-5 \ldots$ & 184 & $1-D-55 \ldots$. & 139 \\
\hline$A-5 \ldots . .$. & 80 & A-55..... & 64 & D-5.... & 194 & D-55... & 142 \\
\hline B-1....... & 89 & B-11........ & 85 & $\mathrm{E}-1 \ldots \ldots$ & 130 & E-11...... & 128 \\
\hline B-2........ & 95 & B-22.......... & 82 & E-2 $\ldots \ldots . .$. & 198 & E-22....... & 145 \\
\hline B-3... & 95 & B-33... & 76 & E-3.... & 212 & E-33... & 167 \\
\hline B-4....... & 96 & B-44...... & 76 & E-4....... & 237 & E-44............. & 181 \\
\hline 2-B-4..... & 98 & 2-B-44.... & 74 & $2-E-4$ & 258 & $2-E-44 \ldots .$. & 177 \\
\hline $1-\mathrm{B}-5 \ldots .$. & 83 & $1-B-55 \ldots . .$. & 73 & $1-\mathbf{E}-5$ & 227 & $1-E-55 \ldots$ & 182 \\
\hline B-5...... & 93 & B-55...... & 76 & E-5........ & 232 & E-55.... & 194 \\
\hline $\mathrm{C}-1 \ldots$ & 124 & C-11... & 140 & & & $A-66 \ldots$ & 72 \\
\hline C-2...... & 149 & C-22..... & 122 & & & B-66... & 91 \\
\hline C-3...... & 160 & C-33...... & 129 & & & C-66........ & 144 \\
\hline C $-4 \ldots \ldots$ & 161 & C-44......... & 129 & & & D-66..... & 165 \\
\hline $2-C-4 \ldots \ldots$ & 170 & $2-C-44 \ldots \ldots$ & 143 & & & E-66.... & 152 \\
\hline $1-C-5 \ldots$. & 159 & $1-C-55 \ldots$ & 120 & & & & \\
\hline C-5......... & 176 & C-55........ & 130 & & & & \\
\hline
\end{tabular}

$a_{5} \mathrm{co} \mathrm{kg} \mathrm{load} \mathrm{applied} \mathrm{to} \mathrm{ro} \mathrm{mm}$ ball for 30 seconds.

$b$ Average of 3 readings.

\section{FACTORS AFFECTING HARDNESS}

From a comparison of the results of the determinations of hardness as summarized in Figs. I 6 to I 9 with the micrographs showing the structure of the materials resulting from the different treatments, it is evident that no simple direct relation between grain size and Brinell hardness exists for carbon steels as does for some alloys; for instance, alpha brass. Grain size is a matter of minor importance with respect to hardness, as compared with some of the other factors involved. 


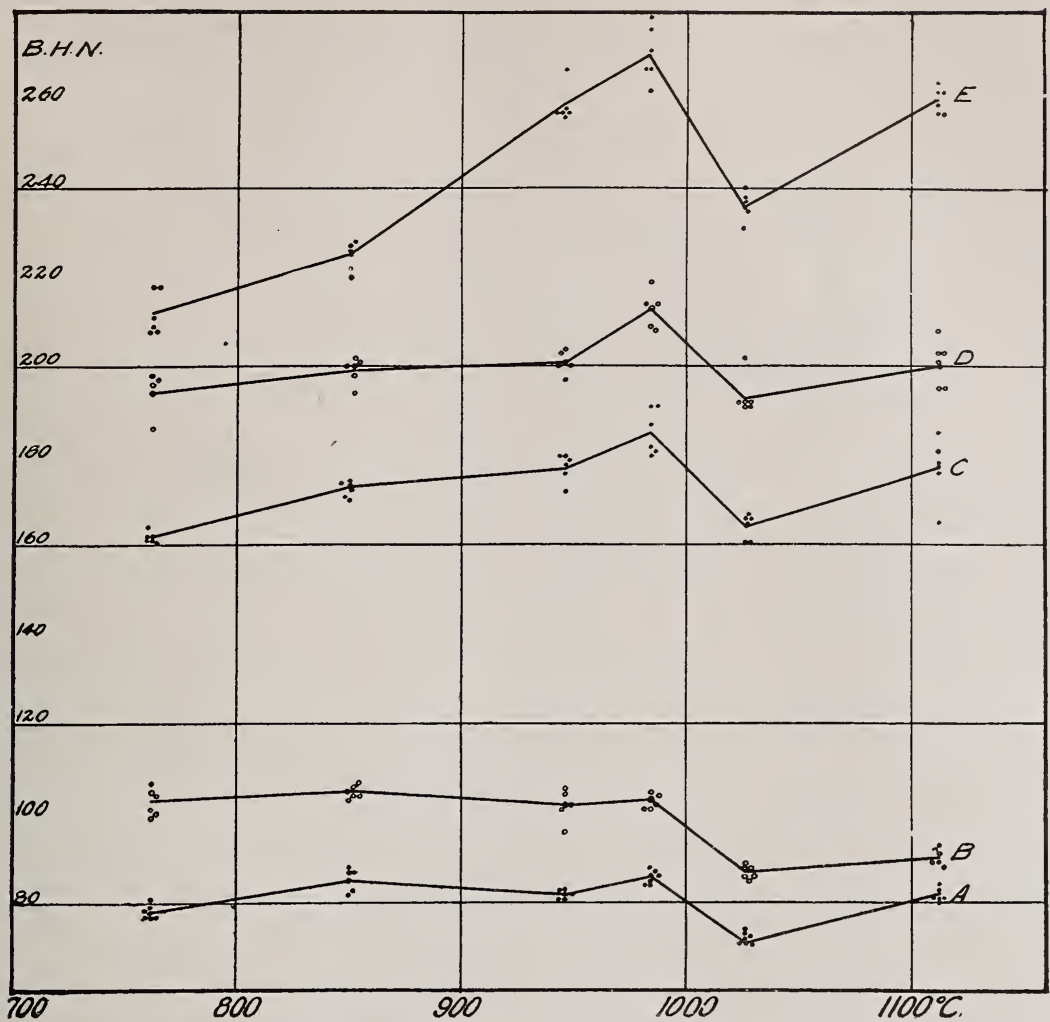

FIG. I6.-Micro-Brinell hardness of the five steels after grain growth

Each specimen was heated six hours at the temperature indicated and cooled in the air

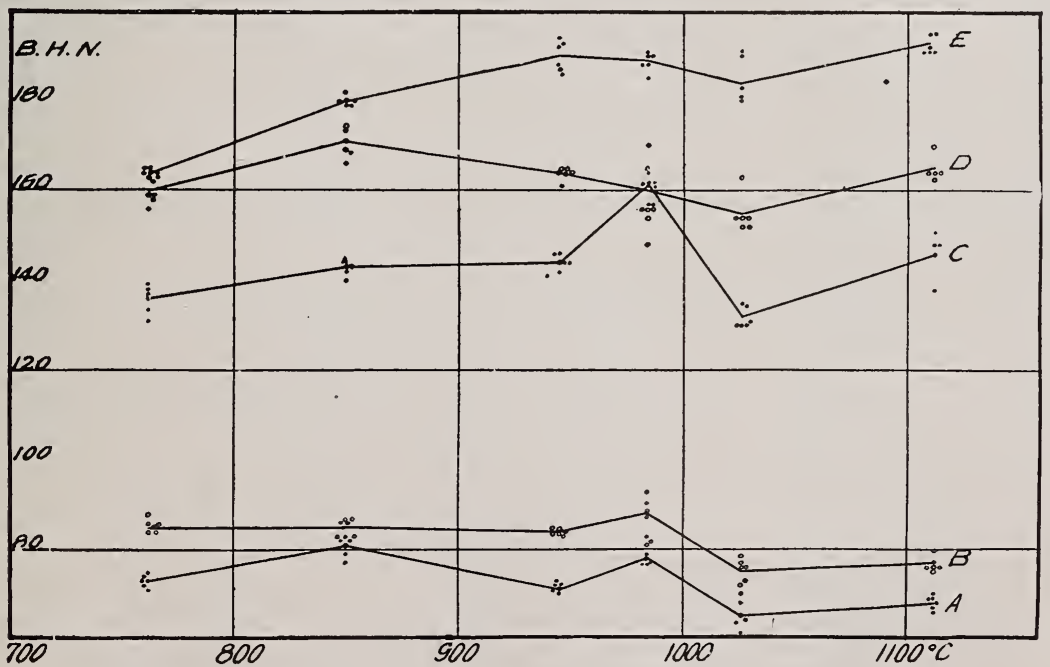

FIG. I7.-Micro-Brinell hardness of the five steels after grai:: growth

Each specimen was heated six hours at the temperature indicated and cooled in the furnace 


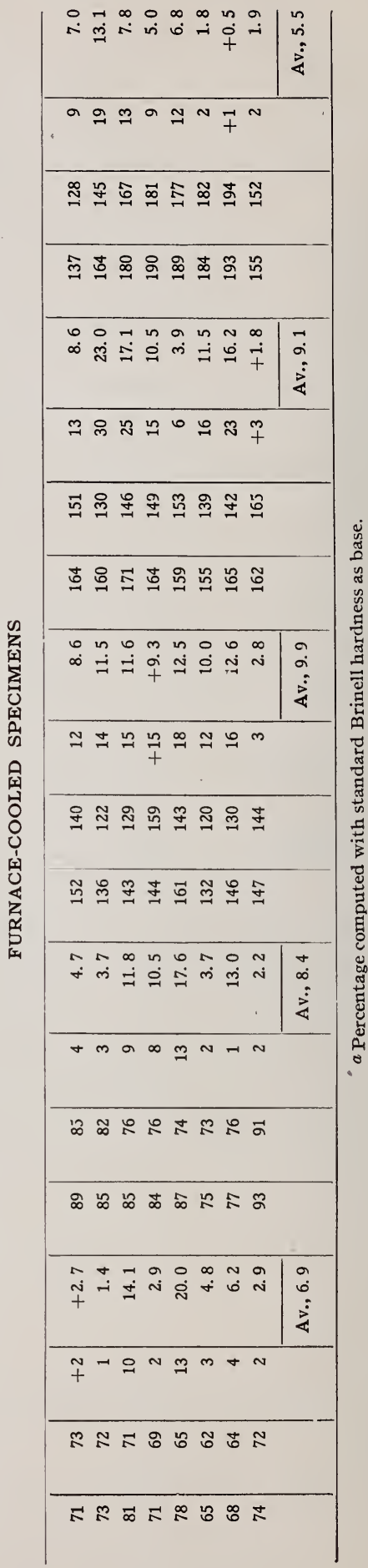




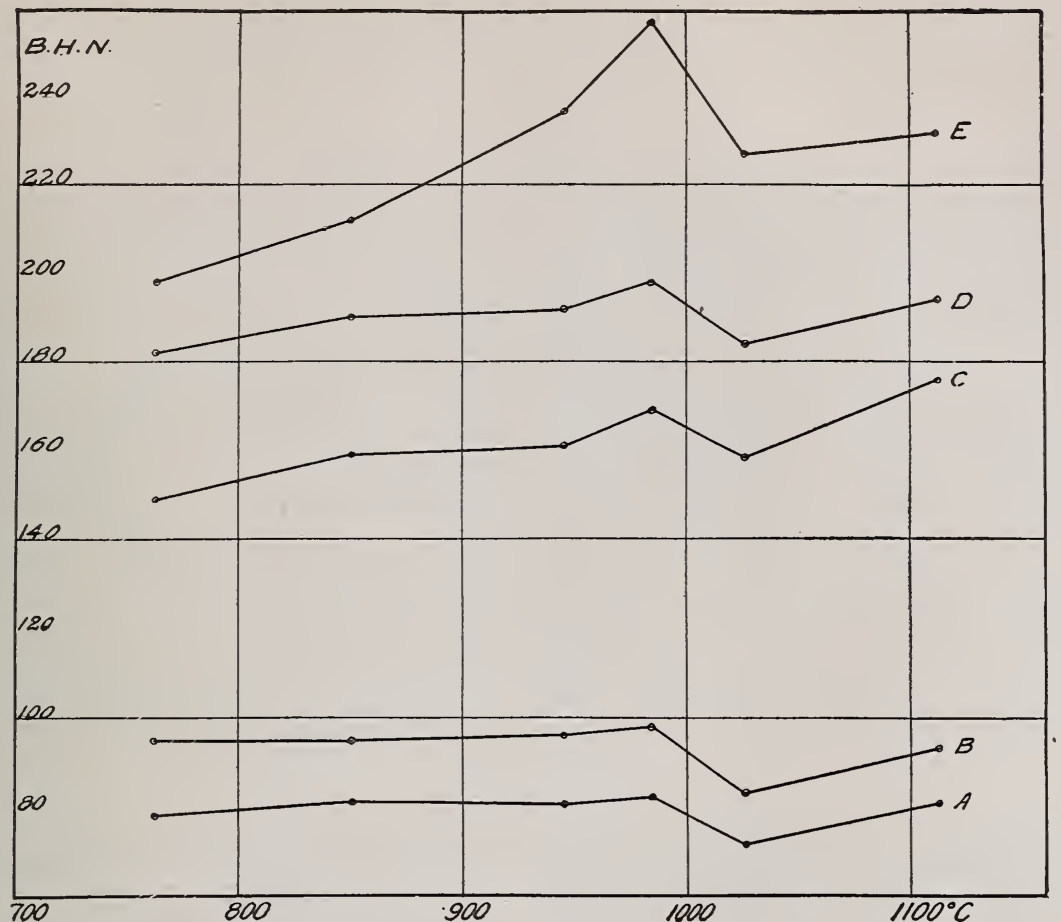

FIG. I8.- "Standard" Brinell hardness of the five steels after grain growth

Each specimen was heated six hours at the temperature indicated and cooled in the air

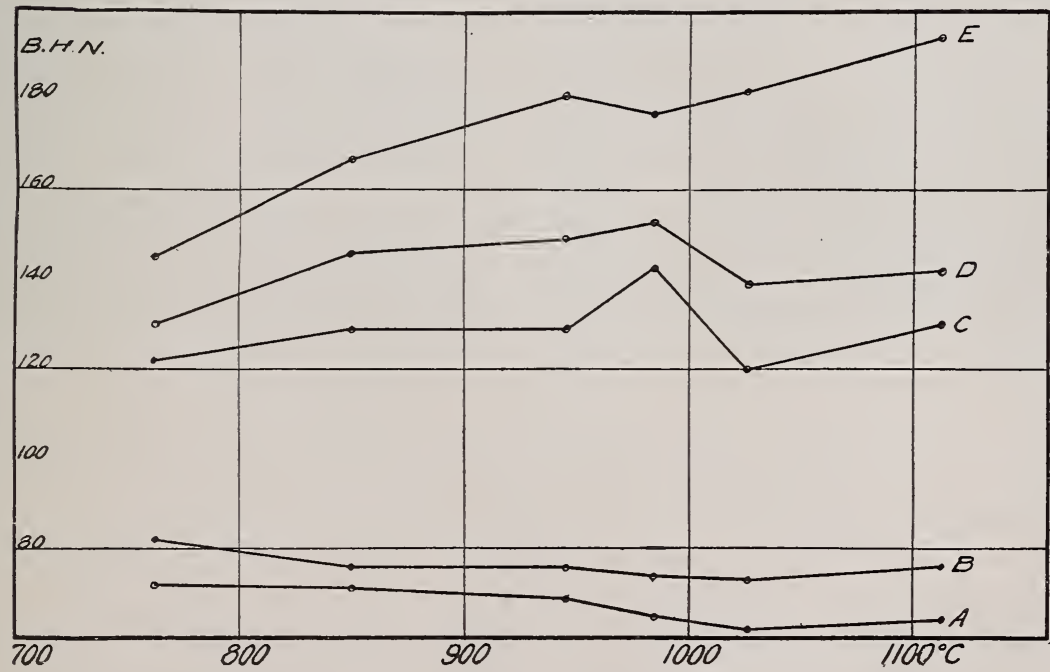

Fig. I9.- "Standard" Brinell hardness of the five steels after grain growth

Each specimen was heated six hours at the temperature indicated and cooled in the furnace 
The purpose of determining the Brinell hardness by the two methods previously described was to show, if possible, the hardness of the grains as individuals or in small aggregates as compared with the average hardness of the material when measured in the usual manner. The results obtained by Portevin ${ }^{11}$ on coarsely grained cast metals and alloys indicates that the hardness of individual crystals is not a constant value even for the same specimen, but it depends upon the relation of the surface bearing the Brinell impression to the internal orientation of the crystal. For convenience in reference the results of the determinations of hardness by the two methods are summarized in Table 6 . With but very few exceptions ( 8 per cent of the total number of determinations), the micro-Brinell hardness is somewhat higher than that obtained in the usual manner. This is in agreement with the results obtained by Goodale and Banks ${ }^{12}$ upon cartridge brass, although the results here obtained by the two methods are in much closer agreement than those referred to. The fact that the hardness as obtained by the use of the small testing set is somewhat higher than that determined by the usual type of apparatus upon the same material is not necessarily to be interpreted as being due to a characteristic behavior of single grains (or small aggregates of grains) as compared with the combined effect of a large number of grains. It is, at least in part, to be attributed to a difference in behavior of the two types of apparatus, characteristic of the two methods. The average difference between the "micro-" and the "standard" Brinell hardness number is somewhat greater for the steels of higher carbon content than for those lov in carbon, particularly in the air-cooled specimens. It is impossible, however, to trace any clear and definite relationship betreen the differences existing between the two sets of hardness numbers and the grain size of the corresponding materials.

In Fig. 20 are given micrographs to illustrate the fact that no appreciable and systematic difference in hardness measured by the micro-Brinell testing apparatus as related to the number and size of grains covered by the impression could be detected. Impressions lying entirely within the limits of a single grain were found to be essentially of the same size as those taken on the same specimen, but overlapping several crystals. The fact that the pearlite grain is not uniform throughout but consists of clearly

${ }^{11}$ A. Portevin, Hardness Tests on Individual Crystals, Rev. de .lét., 12, p. 94; 1915. Also, The mechanical Anisotropy of Coarse-Grained Metals and Alloys and the Brinell Test, C. R., 160, p. 344; Igr5.

12 Proc. A. S. T. II., 19, Pt. II, p. 757; I919. 
defined divisions which may vary very considerably among themselves in size and in orientation is probably largely responsible for this. The micrographs of Fig. 20 also illustrate well the fact that

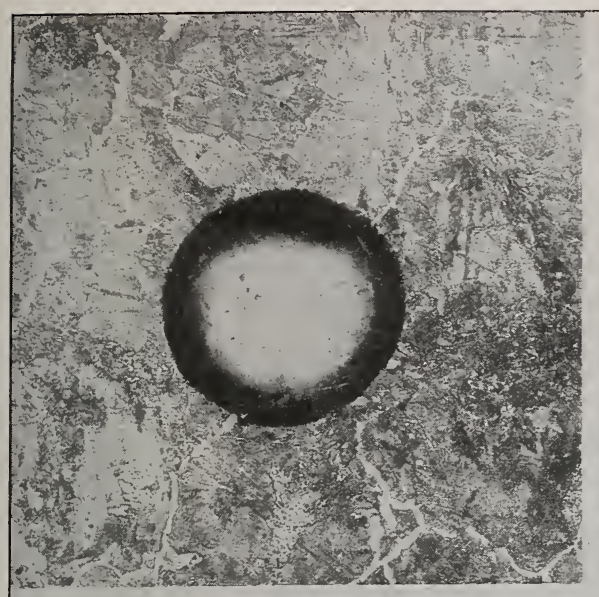

0

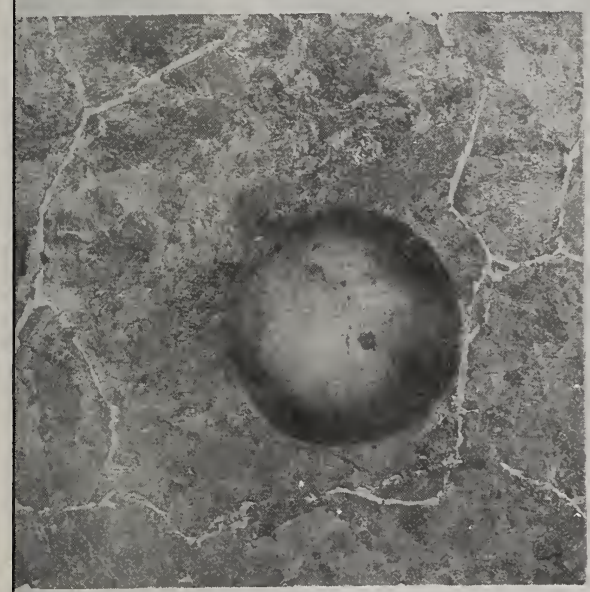

c

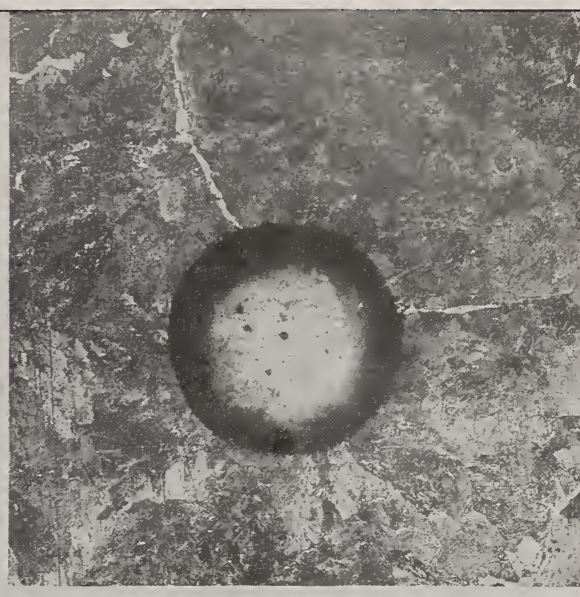

b

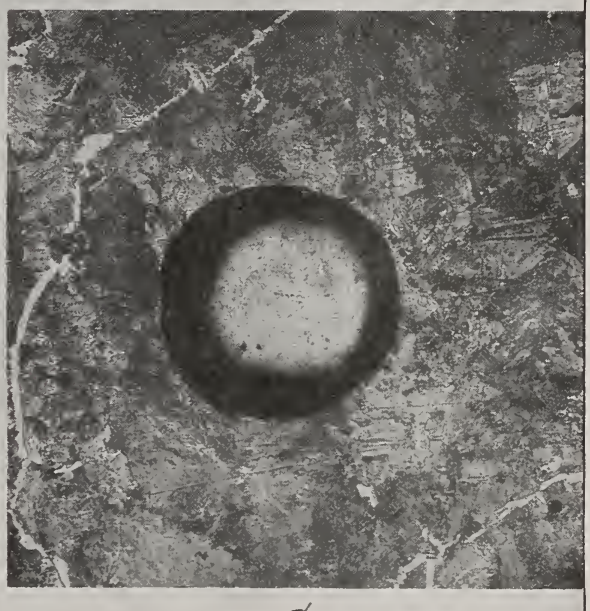

$d$

FIG. 20.- Relation of the impression of the ball in the micro-Brinell test to the grain of the metal of steel $C$, heated six hours at III $2^{\circ} \mathrm{C}$ and air-cooled; $\times 75$ (reduced from $\left.\times 100\right)$

(a)-At junction of four grains; $(b)$-At junction of two grains; $(c)$-Within one grain, near boundary; (d)-Entirely within one grain. All impressions indicate the same hardness number. Etched with 2 per cent alcoholic nitric acia solution

the pearlite grains, particularly when large, must each be considered as an aggregate rather than as a single unit in their properties.

The influence of the very pronounced increase in grain size which occurs in the steel when in the gamma condition upon the 
hardness is indicated in all of the diagrams of Figs. I6 to I9, inclusive. A sharp drop in the hardness curve corresponds to this rapid increase of grain size. The curves also illustrate other features of interest concerning the hardness. The five steels naturally divide themselves into two classes. The two of the lower carbon content ( 0.07 and 0.19 per cent) are quite similar in their behavior; when in the annealed state (that is, cooled in the furnace) the tendency is for the hardness to remain rather uniform, aside from the drop which occurs as a result of the increase in grain size. The effect of cooling the material more rapidly - that is, in air-is to accentuate this drop and to raise the hardness generally throughout. It is of particular interest that the maximum temperature at which the specimen is heated, provided this does not exceed that at which the pronounced increase in grain size occurs, is quite negligible as to the degree of hardness produced upon air cooling. The three steels of higher carbon content $(0.46,0.70$, and I.I 2 per cent) form a group with some striking characteristics in common. The general tendency is for all of these materials to increase in hardness upon annealing; cooling in air accentuates this tendency to a very marked degree. The drop in hardness corresponding to the pronounced increase in grain size which occurs is noticeable in all the specimens; in spite of this drop, however, the general tendency for an increase in hardness with increasing temperature of annealing is still marked. The maximum temperature to which the specimen is heated before cooling either in the furnace or in the air is a factor of importance in determining the hardness. This is due, without doubt, to the larger percentage of carbon in the specimens comprising this group as compared with those of the former one. The rate at which the steel is cooled after the long period of heating is a factor of prime importance in determining its hardness. Figs. $\mathrm{I} 2$ and $\mathrm{I} 3$ show the structural condition of the hardening constituent (pearlite or sorbite) due to the rate at which the material is cooled. Although the specimens which were cooled in the furnace have been given the same designationthat is, "furnace cooled"-it is probable that the rate of cooling was not always the same, but varied somewhat according to the maximum temperature to which the furnace was heated. It may be inferred from the micrographs (Figs. 9 and 10) that a slight decarburization occurred in specimen $\mathrm{E}$ at the high tem- 
peratures, in spite of the precautions taken. Such a slight decarburization, however, would only decrease the slope of the curve slightly and not affect the general results obtained.

The increase in the size of the aggregates of ferrite in the specimens heated at the higher temperatures appears to have but little effect upon the micro-Brinell hardness determinations. A slightly greater tendency toward scattering at the higher temperatures may be observed in the plotted data of the curves, but this is all.

The pronounced tendency shown by all the steels toward an increase in hardness at the highest temperature used as compared with the same steel heated at the next lower temperature is very striking (Figs I6 to I9). Each specimen shows a marked rise in hardness immediately following the pronounced drop, previously attributed to the increased grain size. The material, although "overheated," has not been "burnt," so the increase of hardness can not be attributed to this cause. It is, however, approaching a condition analogous to that resulting from casting, and evidently this pronounced tendency for an increase in hardness is due to some condition similar to that within a casting, which does not reveal itself in the structure alone.

While it is realized that the factors discussed do not account entirely for the phenomena observed as regards Brinell hardness of the materials studied, still it is evident that the conclusion is warranted that grain size is a factor of minor importance. The rate of cooling, together with the accompanying structural and other changes due to the transformations which occur within the metal, are of far greater import. There is no simple relation between grain size and Brinell hardness, as in the metals and alloys of simpler structure.

\section{GRAIN GROWTH UPON ANNEALING AFTER COLD WORKING ${ }^{13}$}

The second method for producing coarsely grained material, previously referred to on page 559, consisted in heating specimens which had been deformed by cold working. The results obtained are included here for their suggestiveness rather than as a complete study of the subject of grain growth after strain. The rapid recrystallization of iron and mild steel, by which extremely coarse crystals can be produced upon annealing after permanent

\footnotetext{
13 The authors are indebted to $R$. W. Woodward for aid in making the mechanical tests discussed in this section.
} 
deformation of the structure, is well know and has formed the subject of several extensive researches. Among these may be mentioned that of Sauveur, ${ }^{14}$ who, following the suggestions of Charpy $^{15}$ and Le Chatelier, ${ }^{16}$ has shown that rapid recrystallization occurs in iron only when the deformation has been carried to a certain "critical" degree. The most extensive study of the subject has been made by Chappell, ${ }^{17}$ who differs in his conclusions from Sauveur.

The specimens used for the production of the coarsely granular areas were somewhat similar to those of Chappell, who employed Frémont's device for obtaining differential stress within the same bar. ${ }^{18}$ These were tapered tension specimens of the size and form shown in Fig. 2r. As materials, two bars of each of the compositions $\mathrm{A}, \mathrm{C}$, and $\mathrm{D}$ (Table $\mathrm{I}$ ) were used; these were annealed for two hours at $650^{\circ} \mathrm{C}$ and cooled in the furnace. This was for the purpose of removing the effect of the cold working which the surface of the specimen received during the necessary machine work and which might affect the subsequent recrystallization. This

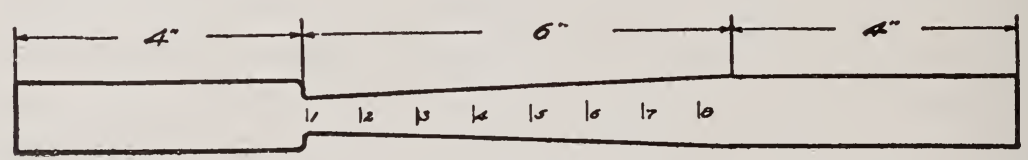

FIG. 2I.-Tension specimen used for differentially straining the steel before annealing

effect may be of considerable magnitude, as has been previously shown. ${ }^{19}$ The specimens, after polishing the sloping surface suitably for microscopic examination, were stressed in tension until rupture occurred; one observer closely watched the polished specimen and the stress was recorded as soon as a roughening of the surface appeared at each of the marked points (Fig. 2r). In this way the necessary stress required to slightly deform the specimen and give rise to the diagonal flow marks, or "Luder's lines," could be measured rather accurately. The maximum stress carried by the bar at each of the marked subdivisions was also calculated from the measured maximum stress borne by the specimen. After microscopic examination of the surface of the strained bars for the occurrence and distribution of slip bands as

${ }^{14}$ Albert Sauveur, Crystalline Growth of Ferrite Below Its Thermal Critical Range, Proc. Int. Asso. Test. Mat., 6th Cong., 2 ; 19 I2.

${ }^{15}$ Georges Charpy, Sur la Mraladie de l’Écrouissage, Rev. de Mét., Memoirs, 7, p. 655; I9ro.

${ }^{16}$ Henri Le Chatelier, Notes de Metallographie, Rev. de Mét., 8, p. 367; 191 I.

${ }_{17}$ C. Chappell, Recrystallization of Deformed Iron, J. Iron and Steel Inst., 89, No. I, p. 460; Igr4.

${ }_{18}$ Frémont, Mesure de la Limite Êlastique des Mrétaux, Bull. Soc. Encouragement Ind. Nat., 55, Pt. II, p. $363 ; 1903$.

${ }^{19}$ H. S. Rawdon, B. S. Tech. Papers, No. 60. 
distinct from the Luder's lines, the specimens were annealed for a period of six hours at $686^{\circ} \mathrm{C}(680-692)$; that is, slightly below the critical range. One bar, $\mathrm{A}-\mathrm{I}, \mathrm{C}-\mathrm{I}$, and $\mathrm{D}-\mathrm{I}$, of each set was cooled in the air, the others, A-II, C-II, and D-II, were allowed to cool in the furnace. It has recently been shown by Hanson ${ }^{20}$ that the time required for the recrystallization of strained metals to occur, at least for the soft metals, aluminum, zinc, etc., is very short. A period of a few minutes at the chosen temperature is sufficient. The object of the long period of annealing was to remove the hardness due to the cold work, as well as to permit the maximum grain growth to occur. It was hoped that in this way specimens which varied only in grain size along the length of the bar might be obtained.

The results of the hardness measurements of the strained-andannealed specimens, together with the data of the tensional stressing, are summarized in Table 7 . The appearance of some of the bars after recrystallization is shown in Fig. 23.

In the case of the low-carbon steel only (A-I and A-II, 0.07 per cent carbon) was the grain found to increase in size during the treatment given. In the specimens of higher carbon content ( 0.40 and 0.70 per cent) no appreciable change could be detected. This confirms Chappell's observations ${ }^{21}$ in this respect. The hardness measurements of specimens $\mathrm{A}-\mathrm{I}$ and $\mathrm{A}-\mathrm{II}$ are in general conformity with those of the bars of which the grain was coarsened by heat alone (Tables 4 and 5 ); that is, a pronounced increase in grain size is accompanied by a lowering of the Brinell hardness. In the other specimens ( $C$ and $D$ ) the hardening effect of the straining was removed by the prolonged heating, and the specimen showed no pronounced differences in hardness along its length. In some cases the end of the bar which was most severely strained was found to be somewhat softer than the other, although no perceptible increase has occurred in the size of the grain in such specimens. Although the steels were heated at a temperature considerably below that of the $\mathrm{A}_{1}$ transformation, all the specimens cooled in air were noticeably harder than those allowed to cool in the furnace.

The results of the tension test throw some additional light upon the conditions necessary for the rapid recrystallization of soft steel upon annealing after strain.

\footnotetext{
${ }^{20}$ D. Hanson, Rapid Recrystallization in Deformed Nonferrous Metals, J. Inst. Metals, 20, No. 2, p. I4I; I9I8.

${ }^{21} \mathrm{~J}$. Iron and Steel Inst., 89, No. I, p. 460; 19r4,
} 


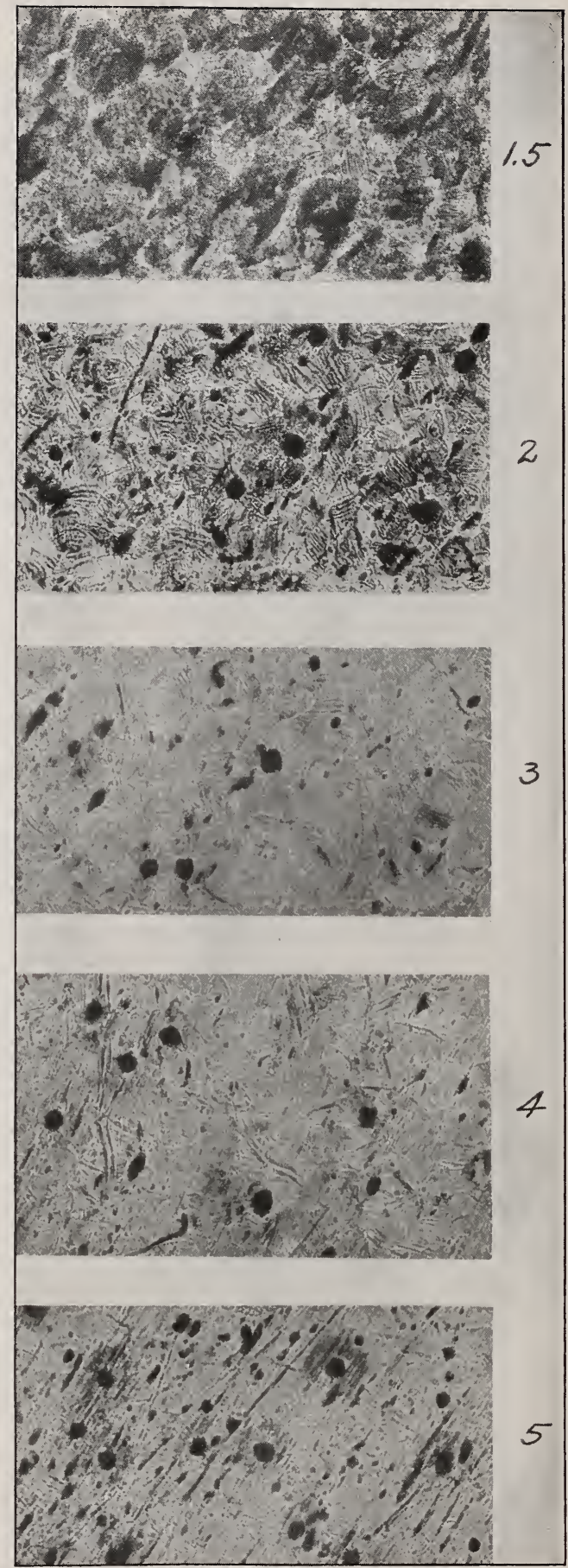

FIG. 22.-Condition of the surface of tapered tension specimen of 0.07 per cent carbon steel A after straining; $\times$ IOO

The figures indicate the position of the micrograph on the bar (Fig. 21). No slip bands were found beyond mark 


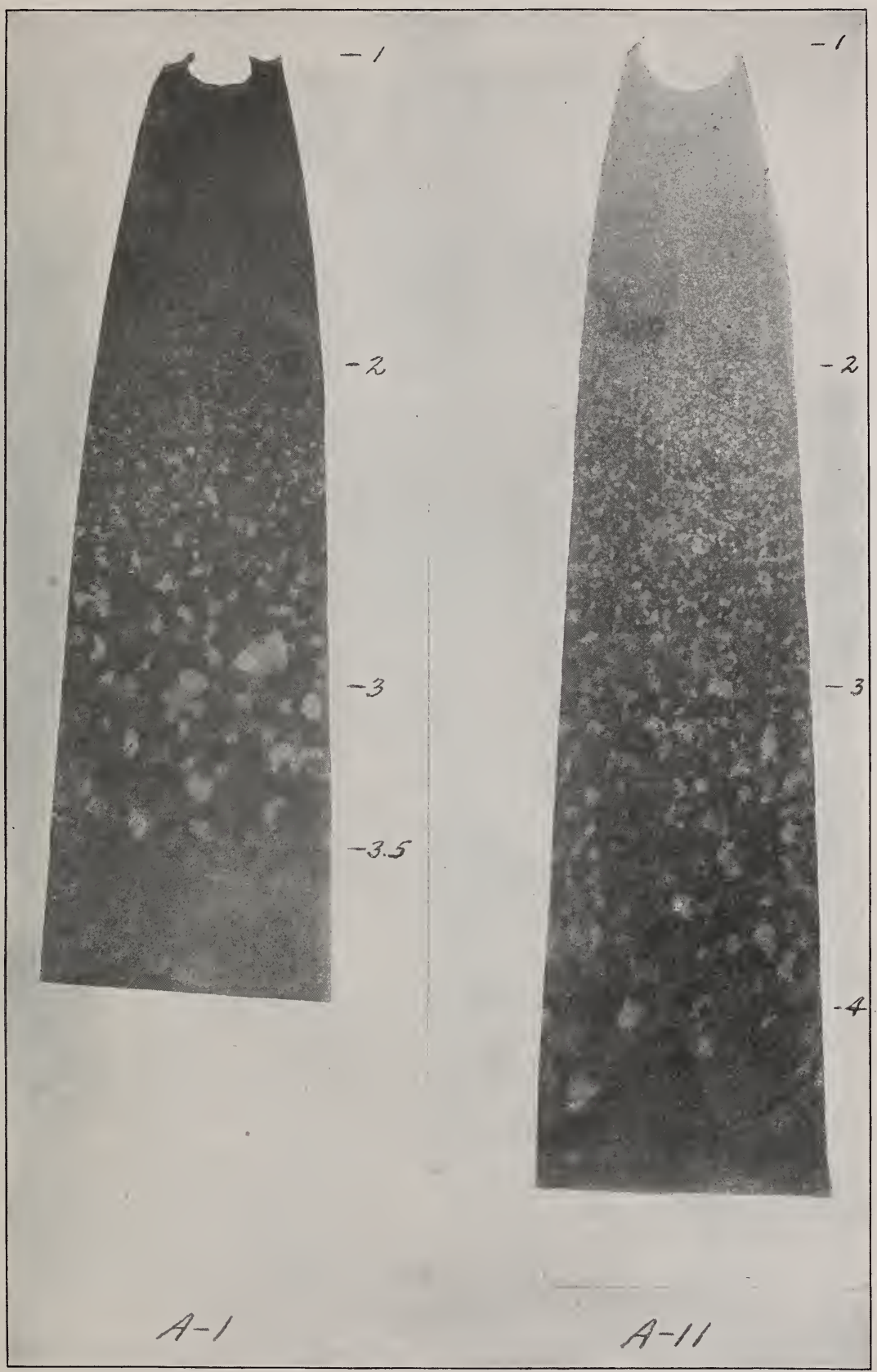

FIG. 23.-Grain growth produced by the low-temperature annealing of steel $A$ after strain; $\times 2$

The specimens were annealed six hours at $686^{\circ} \mathrm{C}$ after being stressed in tension till rupture occurred. The numbers correspond to the subdivisions (Fig. $2 \mathrm{I}$ ). Maximum grain size in A-r corresponds in applied stress which was 26.8 per cent greater than the elastic limit and in A-II, 27 per cent. Eitched with 2 per cent alcoholic nitric acid 
TABLE 7.-Brinell Hardness of Steel, Annealed after Straining

\begin{tabular}{|c|c|c|c|c|c|c|c|c|c|c|c|}
\hline Steel $a$ & $\begin{array}{l}\text { Divi- } \\
\text { sion } b\end{array}$ & $\begin{array}{c}\text { Stress } \\
\text { to per- } \\
\text { ma- } \\
\text { nently } \\
\text { deform } \\
\text { mate- } \\
\text { rial }\end{array}$ & $\begin{array}{l}\text { Maxi- } \\
\text { mum } \\
\text { stress }\end{array}$ & $\begin{array}{l}\text { Micro- } \\
\text { Brinell } \\
\text { hard- } \\
\text { ness } c\end{array}$ & $\begin{array}{l}\text { Stand- } \\
\text { ard } \\
\text { Brinell } \\
\text { hard- } \\
\text { ness d }\end{array}$ & Steel $a$ & $\begin{array}{l}\text { Divi- } \\
\text { sion } b\end{array}$ & \begin{tabular}{|} 
Stress \\
to per- \\
ma- \\
nently \\
deform \\
mate- \\
rial
\end{tabular} & $\begin{array}{l}\text { Maxi- } \\
\text { mum } \\
\text { stress }\end{array}$ & $\begin{array}{l}\text { Micro- } \\
\text { Brinell } \\
\text { hard- } \\
\text { ness } c\end{array}$ & $\begin{array}{l}\text { Stand - } \\
\text { ard } \\
\text { Brinell } \\
\text { hard- } \\
\text { ness } d\end{array}$ \\
\hline \multirow{15}{*}{$A-1 \ldots \ldots}$. & & Lbs/in & Lbs/in ${ }^{2}$ & & & \multirow{15}{*}{ C-11....... } & & Lbs/in ${ }^{2}$ & Lbs/in ${ }^{2}$ & & \\
\hline & 1 & 27540 & 49280 & 79 & ..... & & 1 & 45385 & 97370 & $148^{4}$ & $\cdots$ \\
\hline & 1.5 & ....... & 43430 & 84 & 75 & & 1.5 & 45530 & 89045 & 162 & 163 \\
\hline & {$\left[\begin{array}{l}e \\
2\end{array}\right.$} & 26350 & 40325 & 112 & 77 & & 2 & 47800 & 82730 & 158 & 150 \\
\hline & 2.5 & 27180 & 35640 & 117 & 81 & & 2.5 & 50600 & 77920 & 156 & 156 \\
\hline & 3 & 27800 & 35670 & 121 & 89 & & 3 & 47870 & 74200 & 154 & 150 \\
\hline & {$[\because 3.5$} & 27180 & 33985 & 119 & 94 & & 3.5 & 51960 & 70480 & 153 & 147 \\
\hline & 4 & 27150 & 32530 & 127 & 95 & & 4 & 51140 & 67525 & 148 & 146 \\
\hline & 4.5 & $\ldots$. & 31255 & 126 & 94.5 & & 4.5 & 49550 & 64450 & 151 & 147 \\
\hline & 5 & 27100 & 30010 & 127 & 94 & & 5 & 46020 & 61850 & 154 & 144 \\
\hline & 5.5 & $\ldots \ldots$ & 28930 & 126 & 97 & & 5.5 & 47070 & 58340 & 153 & 140 \\
\hline & 6 & 25950 & 27950 & 124 & 96 & & 6 & 44750 & 57080 & 155 & 140 \\
\hline & 6.5 & 26430 & 27030 & 127 & 95 & & 6.5 & 45800 & 55020 & 161 & 140 \\
\hline & 7 & ....... & 26205 & 127 & 94 & & 7 & 46320 & 53290 & 162 & 144 \\
\hline & 7.5 & 25200 & 25450 & 126 & $\cdots$ & & 7.5 & 45150 & 51390 & 169 & 142 \\
\hline Average.... & & 26790 & 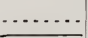 & & 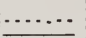 & \multirow{2}{*}{$\begin{array}{l}\text { Average.. } \\
\text { D-1....... }\end{array}$} & …. & 47560 & ……... & - & \\
\hline \multirow[t]{14}{*}{$\Lambda-11 \ldots \ldots}$. & 1 & & 48800 & $\overline{74}$ & $\overline{\cdots . .}$ & & 1 & 56940 & 114260 & 154 & 166 \\
\hline & 1.5 & & 45020 & 81 & 74 & & 1.5 & ....... & 108660 & 162 & 162 \\
\hline & 12 & 26650 & 42075 & 86 & 76 & & 2 & 56320 & 95920 & 167 & 163 \\
\hline & 2.5 & 26480 & 41140 & 83 & 74 & & 2.5 & 51165 & 91330 & 154 & 161 \\
\hline & 3 & 28390 & 37790 & 107 & 76 & & 3 & 51160 & 86010 & 165 & 160 \\
\hline & 3.5 & 27790 & $36 \quad 120$ & 112 & 79 & & 3.5 & 47540 & 81670 & 165 & 161 \\
\hline & 4 & 27010 & 34240 & 111 & 81 & & 4 & 51890 & 77655 & 167 & 159 \\
\hline & 4. 5 & 27720 & 32815 & 110 & 89 & & 4. 5 & 51490 & 74500 & 170 & 159 \\
\hline & 5 & ........... & $\begin{array}{ll}31 & 340\end{array}$ & 109 & 88 & & 5 & 51800 & 72000 & 173 & 159 \\
\hline & 5.5 & 27280 & $\begin{array}{lll}30 & 040\end{array}$ & 108 & 87 & & 5.5 & 52240 & 68380 & 182 & 159 \\
\hline & 6 & 26500 & 28860 & 111 & 87 & & 6 & 52240 & 65875 & 181 & 159 \\
\hline & 6.5 & 26820 & 27780 & 109 & 86 & & 6.5 & 52420 & 63490 & 184 & 160 \\
\hline & 7 & 25960 & 26730 & 114 & 86 & & 7 & 52360 & 61250 & 184 & 160 \\
\hline & 7.5 & 25650 & 25740 & 116 & 88 & & 7.5 & ......... & 59120 & 183 & 165 \\
\hline Average. & & 26930 & …..... & $\cdots$ & 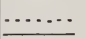 & Average.. & $\cdots$ & 52290 & ......... & - & ........ \\
\hline \multirow[t]{14}{*}{ C $-1 \ldots \ldots . .}$. & 1 & 51330 & $\overline{99290}$ & $\cdots$ & 147 & \multirow[t]{14}{*}{$\mathrm{D}-11 \ldots$} & 1 & 56735 & 115450 & ..... & 165 \\
\hline & 1.5 & 48510 & $\begin{array}{|ll|}84 & 140\end{array}$ & 156 & 156 & & 1.5 & ....... & 106540 & 166 & 155 \\
\hline & 2 & 46570 & 82410 & 157 & 155 & & 2 & 52030 & 98835 & 164 & 160 \\
\hline & 2.5 & 47000 & 77440 & 158 & 150 & & 2.5 & 51200 & 93710 & 164 & 159.5 \\
\hline & 3 & 47160 & 73640 & 166 & 153 & & 3 & 51860 & 88060 & 167 & 157.5 \\
\hline & 3.5 & 47060 & $\begin{array}{ll}70 & 260\end{array}$ & 166 & 147 & & 3.5 & 52120 & 84960 & 165 & 158 \\
\hline & 4 & 47530 & 67390 & 154 & 147 & & 4 & 52090 & 80700 & 165 & 153 \\
\hline & 4. 5 & 47310 & 64585 & 153 & 152 & & 4.5 & 52610 & 77270 & 168 & 157.5 \\
\hline & 5 & 46620 & 61875 & 152 & 149 & & 5 & 52000 & 74.300 & 168 & 161 \\
\hline & 5.5 & 47750 & 59725 & 160 & 147 & & 5.5 & 53870 & 73270 & 176 & 161 \\
\hline & 6 & 47270 & 57455 & 165 & 152 & & 6 & 51920 & 68490 & 172 & 161 \\
\hline & 6.5 & 47180 & 55530 & 168 & 149 & & 6.5 & 51930 & 65870 & 178 & 160 \\
\hline & 7 & 47095 & 53574 & 165 & 150 & & 7 & 51760 & 63650 & 176 & 161 \\
\hline & 7.5 & 46880 & $\begin{array}{lll}51 & 730 \\
\end{array}$ & 168 & 147 & & 7.5 & & 60890 & 181 & 163 \\
\hline Average... & & 47520 & & & & Average.. & & 52510 & & & \\
\hline
\end{tabular}

$a$ Specimens A-I, C-I, D-I (composition, Table I) were cooled in the air after the final annealing. Specimens A-II, C-II, D-II (composition, Table I) were cooled in the furnace after the final annealing. $b$ See Fig. $2 \mathrm{I}$.

$c_{15} \mathrm{~kg}$ load, $\frac{1}{16}$-inch ball, pressure applied for 30 seconds.

d $500 \mathrm{~kg}$ load, ro $\mathrm{mm}$ ball, pressure applied for 30 seconds.

e....... $e^{\prime}$ Zone of pronounced crystal growth, Fig. 23.

$f . . . . . f^{\prime}$ Zone of pronounced crystal growth, Fig. 23. 
The stress necessary for the appearance of the "flow" or "stress." lines at different positions along the tapered specimen gives a rather accurate measurement of the "elastic limit," as defined in this way. The microscopic examination of the surface of the specimen after straining shows that the metal must be stressed considerably more than this value in order to produce the distortion within the crystal familiarly known as "slip bands." Only in those portions of the bar in which slip bands were found was there an increase of crystal size on annealing. The converse, however, was found by observation not to be true. A comparison of the maximum stress borne by the bar at different points along its length with the "elastic limit" as defined by the test demonstrates that, for pronounced coarsening of the grain at the temperature used, the "elastic limit" must be exceeded by amounts varying from about 25 to 55 per cent. In A-I the region of pronounced growth corresponds to a stress exceeding the "elastic limit" by 26.8 to 52 per cent; in A-r I, 27 to 56 per cent. In both cases, the zone of crystals of maximum size corresponds closely to the lower percentage given above. It is evident that when the first roughening of the surface appears-that is, when the Luder's lines ( $45^{\circ}$ flow lines) are formed-the individual crystals of the material have not yet been permanently deformed to any appreciable extent, as no slip bands were found above division 5 for the low-carbon steel (Fig. 22), or beyond division 3 for each of the other steels (Fig. 24). The material was permanently strained, however, along the tapered length sufficiently to produce the characteristic appearance due to the Luder's lines (Fig. 25) and to permit a determination of the stress at the "elastic limit" being made (Table 7).

When the metal is stressed considerably more than the limits given above, so that the crystals are very badly distorted, as shown by the pronounced roughening of the surface by the slip bands (Fig. 22), the grain size after annealing, although considerably larger than originally, is still far below the maximum attained in other parts of the specimen.

\section{SUMMARY}

I. The Brinell hardness was determined for five steels varying in carbon content from a very low value to somewhat above I per cent. Each of the steels was treated so as to produce wide variations in grain size, and the hardness was determined in each condition. 
2. Upon heating for six-hour periods no very appreciable increase in the grain size occurs until the $\mathrm{Ac}_{3}$ transformation in the steel has occurred. The change in grain size often appears to be a very abrupt one; that is, it takes place within a rather narrow range of temperature.

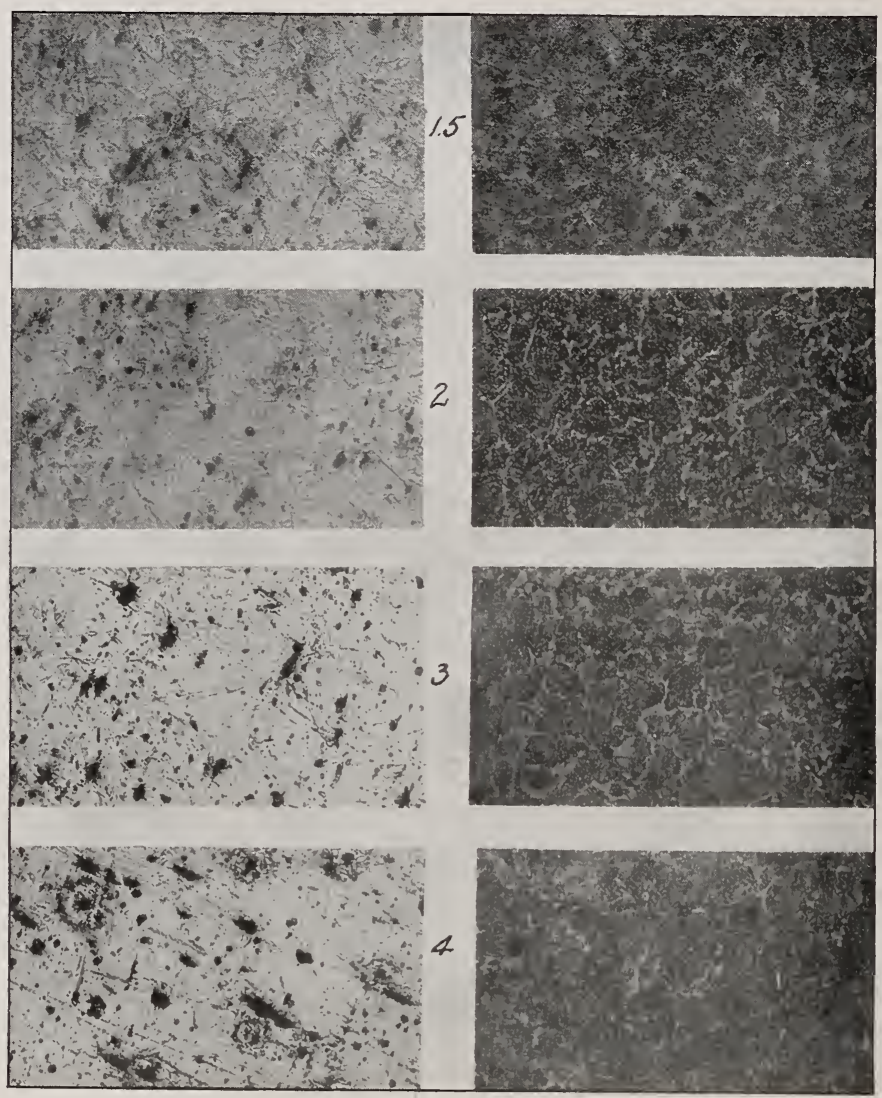

FIG. 24.-Condition of tapered tension specimen $C$ after straining (Table 7); $\times 75$ (reduced from $\times 100)$

The figures refer to the position on the bar (Fig. 2 $:$ ). Slip bands were found on the surface as far as position 3. No grain growth upon annealing occurred, however, as a result of this deformation. Etched with 2 per cent alcoholic nitric acid (for the micrographs at the right, others unetched)

3. Two methods were used for obtaining the Brinell hardness, one of which was intended to give the hardness of individual crystals or small aggregates as distinct from the average hardness of the material.

4. The results of the two methods show no appreciable or consistent difference between the hardness of small groups of crystals and the average hardness for the steels investigated. 
5. Although it was impossible to obtain an accurate numerical grain-size determination for many of the specimens, the micrographic examination indicates that there is no simple and direct relation between grain size and Brinell hardness number for carbon steels. A very pronounced increase in grain size is usually accompanied by a decrease in hardness. On the whole, however, grain size appears to be a factor of minor importance in determining the Brinell hardness of carbon steels of the types investigated.

6. The general effect of heating the steel-that is, upon the properties of the metal after cooling - is to harden it appreciably. This increase is noticeable in spite of a pronounced drop in hardness which accompanies an abrupt increase in grain size. This tendency toward hardening upon heating is not shown by low carbon steels to any extent, thus suggesting that this change in hardness is not a function of the grain size.

7. The rate at which steels are cooled, and consequently the structural condition of the hardening constituent, affects the hardness much more than any other factor.

8. The hardness measurements upon materials in which a pronounced differential grain growth has been produced by low-temperature annealing after straining the metal are in general accord with

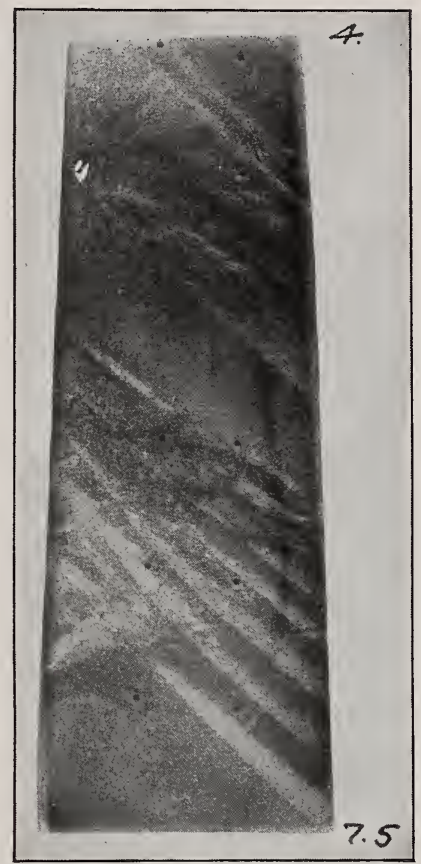

Fig. 25.-Portion of the tapered tension specimen, steel $A$, from Div. 2 to 7.5 (Fig. 2I) after straining

The $45^{\circ}$ flow lines (Luder's lines) are very prominent; some roughening due to slip bands may also be seen. Specimen is unetched and is slightly larger than natural size the results obtained upon the same steels in which the grain was coarsened by heat alone.

9. Incidental to the study of the hardness of steels coarsened by annealing after permanent strain, some data were obtained relative to the magnitude of the necessary stress required to cause pronounced grain growth upon annealing such strained metal below the $\mathrm{Ac}_{1}$ transformation temperature.

Washington, April 28, 1920. 




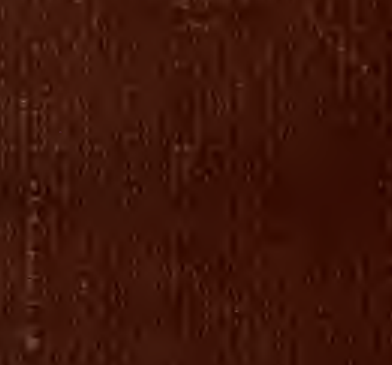

